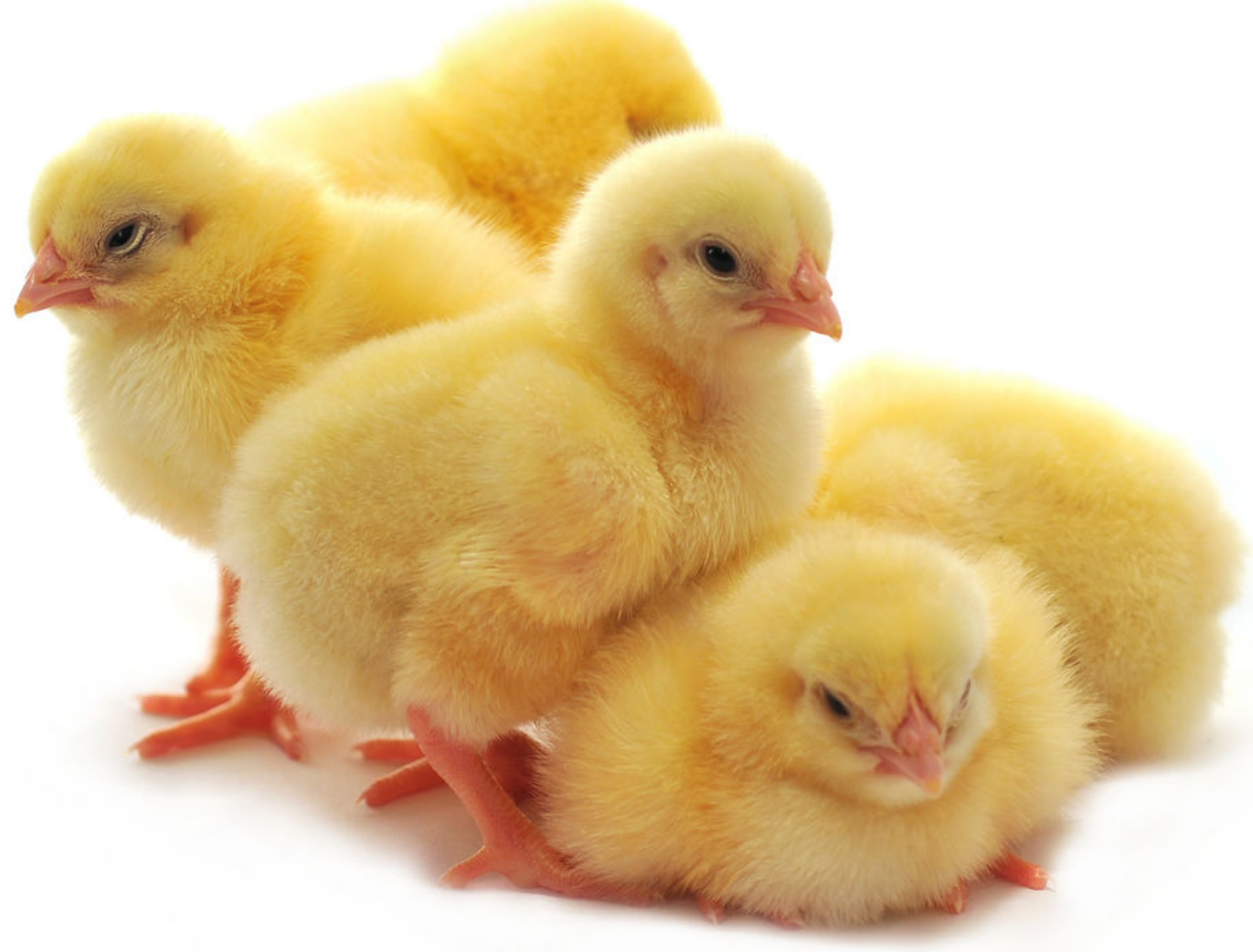

Nutritional interventions to modulate immune competence in broilers and correlation to quantitative disease phenotype after Necrotic enteritis challenge.

Marinus van Krimpen, David Lamot, Ralph Kok, Arjan Hoekman, Marcel Hulst, Alex Bossers, Annemarie Rebel, Mari Smits, Dirkjan Schokker

\title{
WAGENINGEN
}

UNIVERSITY \& RESEARᄃH 



\section{Nutritional interventions to modulate immune competence in broilers and correlation to quantitative disease phenotype after Necrotic enteritis challenge.}

Marinus van Krimpen ${ }^{1}$, David Lamot ${ }^{2}$, Ralph Kok ${ }^{3}$, Arjan Hoekman ${ }^{1}$, Marcel Hulst ${ }^{1}$, Alex Bossers ${ }^{3}$, Annemarie Rebel $^{3}$, Mari Smits ${ }^{1,3}$, Dirkjan Schokker ${ }^{1}$

1 Wageningen Livestock Research, Wageningen, the Netherlands

2 Cargill Animal Nutrition Innovation Center Velddriel, the Netherlands

3 Wageningen Bioveterinary Research, Lelystad, the Netherlands

This research was conducted by Wageningen Bioveterinary Research and Wageningen Livestock Research commissioned and funded by the Ministry of Economic Affairs, within the Public Private Partnership Feed4Foodure, part B 'Nutrition, intestinal health, and immunity' (project number BO-22.04-002-001) 
Marinus van Krimpen ${ }^{1}$, David Lamot ${ }^{2}$, Ralph Kok ${ }^{3}$, Arjan Hoekman ${ }^{1}$, Marcel Hulst ${ }^{1}$, Alex Bossers ${ }^{3}$, Annemarie Rebel ${ }^{3}$, Mari Smits ${ }^{1,3}$, Dirkjan Schokker ${ }^{1}$ 2017; Wageningen Livestock Research, Report 1071.

This report can be downloaded at https://doi.org/10.18174/428321 of op www. wur. nl/livestock-research (onder Wageningen Livestock Research publicaties).

(C) 2017 Wageningen Livestock Research

Postbus 338, 6700 AH Wageningen, T 03174839 53, E info.livestockresearch@wur.nl, www. wur. nl/livestock-research. Wageningen Livestock Research is onderdeel van Wageningen University \& Research.

All rights reserved. No part of this publication may be reproduced and/or made public, whether by print, photocopy, microfilm or any other means, without the prior permission of the publisher or author.

De certificering volgens ISO 9001 door DNV onderstreept ons kwaliteitsniveau. Op als onze onderzoeksopdrachten zijn de Algemene Voorwaarden van de Animal Sciences Group van toepassing. Deze zijn gedeponeerd bij de Arrondissementsrechtbank Zwolle.

Wageningen Livestock Research Report 1071 


\section{Inhoud}

$\begin{array}{ll}\text { Inhoud } & 3\end{array}$

$\begin{array}{lr}\text { Foreword } & \mathbf{5}\end{array}$

$\begin{array}{lr}\text { Short summary } & 7\end{array}$

$\begin{array}{llr}1 & \text { Introduction } & 9\end{array}$

1.1 Importance of early life $\quad 9$

$\begin{array}{lll}1.2 & \text { Feed interventions } & 9\end{array}$

1.2.1 Positive and negative control 9

1.2.2 Antibiotics (amoxicillin - drinking water) 10

$\begin{array}{lll}1.2 .3 & \text { Rye }(25 \%) & 10\end{array}$

1.2.4 Butyrate 11

$\begin{array}{lll}1.3 & \text { Objective } & 11\end{array}$

$2 \quad$ Materials and Methods $\quad 12$

$\begin{array}{lll}2.1 & \text { Experimental design } & 12\end{array}$

2.2 Animal experiment $\quad 12$

2.2.1 Animal housing and management 12

2.2.2 NE challenge $\quad 12$

$\begin{array}{lll}2.2 .3 & \text { Diets and nutritional interventions } & 13\end{array}$

2.2.4 Performance and sampling 14

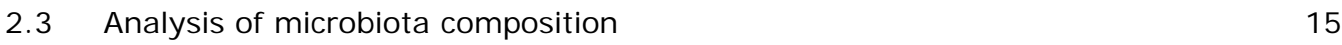

$\begin{array}{lll}2.3 .1 & \text { DNA isolation } & 15\end{array}$

2.3.2 Sequence analyses of 16S rDNA $\quad 15$

2.4 Gene expression of intestinal tissue 15

2.4.1 RNA isolation $\quad 15$

2.4.2 Microarrays: Labelling and hybridization procedure $\quad 15$

2.5 Histology 15

2.5.1 Morphometric measurements $\quad 15$

2.5.2 Periodic acid-Schiff / alcian blue staining (goblet cells) 16

2.6 Statistical analyses 16

2.6.1 Performance data, lesion scores, mortality 16

2.6.2 Microbiota data 16

2.6.3 Gene expression (microarray data) 17

$\begin{array}{lll}2.6 .4 & \text { Histology } & 17\end{array}$

3.1 Effect of nutritional interventions on performance $\quad 18$ $\begin{array}{ll}\text { Body weight } & 18\end{array}$

Performance 0 to $7 \mathrm{~d}$ of age: Provision of (dietary) treatments 18

Performance 7 to $16 \mathrm{~d}$ of age: Necrotic enteritis challenge $\quad 18$

Performance 0 to $35 \mathrm{~d}$ of age: Overall study period 20

$\begin{array}{ll}\text { Mortality and culling } & 20\end{array}$

3.2 Effect of nutritional interventions on jejunal microbiota 20

Microbiota diversity $\quad 20$

Redundancy analysis $\quad 21$ 
Microbiota composition on genus level

3.3 Effect of feed interventions on transcriptomics in jejunum at day 7

3.3.1 Differential gene expression between feed interventions and control broilers

3.3.2 Pathway analysis

3.4 Effect of feed interventions on jejunal histology 32

3.5 Effect of feed interventions on lesion scores 33

4

$\begin{array}{ll}\text { Discussion } & 34\end{array}$

$4.1 \quad$ NE Challenge $\quad 34$

4.2 Antibiotics $\quad 34$

4.3 Rye 36

4.4 Butyrate $\quad 36$

$\begin{array}{lll}4.5 & \text { Beta-glucans } & 37\end{array}$

$\begin{array}{lll}4.6 & \text { Quantitative disease phenotype } & 37\end{array}$

$\begin{array}{lll}4.7 & \text { Concluding remarks and future research } & 38\end{array}$ 


\section{Foreword}

Feed4Foodure is a public-private partnership between the Dutch Ministry of Economic Affairs, a consortium of various organizations within the animal production chain and Wageningen UR Livestock Research / Wageningen Bioveterinary Research. Feed4Foodure aims to contribute to sustainable and healthy livestock farming in the Netherlands, simultaneously strengthening our competitive position on the global market. The Feed4Foodure program line "Nutrition, intestinal health, and immunity", aims to contribute to a reduction in the use of antibiotics in livestock farming by increasing general (gut) health and disease resistance. The main goals are to develop innovative measurement techniques for (gut) health in animal husbandry.

The current report describes an experiment that was conducted within VDI workpackage-11 as in kind contribution of Cargill.

For the current study, scientists of Wageningen UR Livestock Research and Wageningen Bioveterinary Research worked together with representatives from the various private partners of VDN (Vereniging Diervoederonderzoek Nederland). The authors thank the industry partners of the project team for their worthwhile input.

On behalf of Prof. Dr. Mari Smits, leader of the Feed4Foodure program line "Nutrition, intestinal health, and immunity".

Dr. Dirkjan Schokker

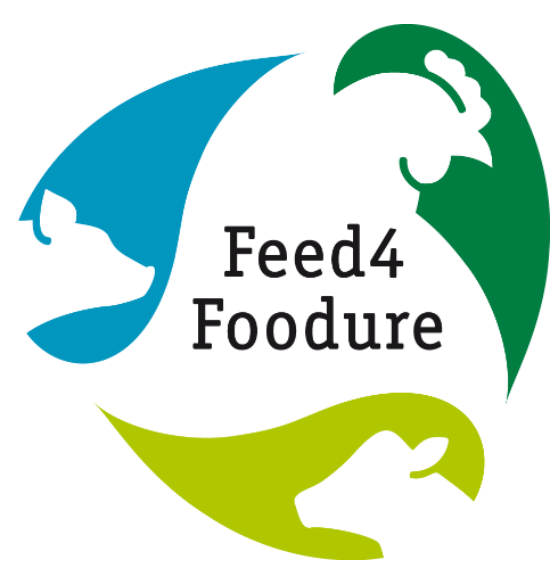




\section{Short summary}

This study investigated the effect of four different nutritional interventions, applied during the first week of life, on immune competence parameters of broiler chickens. The four (dietary) interventions were antibiotics in the drinking water, $25 \%$ inclusion of rye in the feed, beta-glucans from Saccharomyces cerevisiae, and coated butyrate. Broiler chickens (between 1 and 2 weeks of age) were subjected to a Necrotic Enteritis (NE) challenge. A positive and negative control treatment (challenged vs. non-challenged chickens, respectively) was included to estimate the effect of the NE challenge. It was hypothesized that applying a nutritional intervention in the first week of life would affect the microbiota colonization, immune system programming, and consequently the quantitative disease phenotype (lesions scores as a result of the NE challenge).

The NE challenge did affect the overall performance during the first 2 weeks post-challenge. The antibiotics group showed significant effects on different biological levels: (temporary) increased performance, deviating microbiota composition, increased gene expression in barrier function processes, whereas decreased gene expression in immune related processes, and a higher villi to crypt ratio compared to the (un)challenged control treatment. In the other treatments only significant differences in bacterial genera were observed.

In conclusion, this study has shown that it is probable to disturb the gut system development, whereby giving antibiotics (amoxicillin) gives an effect on multiple biological levels. In addition, the other dietary perturbations, i.e. change in feed composition ( $25 \%$ inclusion of rye), feed additives (beta-glucans or coated butyrate) only affected the microbiota composition to some extent. 


\section{Introduction}

\section{$1.1 \quad$ Importance of early life}

According to EFSA/ECDC [1], microbial resistance to antibiotics is an alarming threat, putting human and animal health in danger. Agricultural use of antibiotics can be recognized as one of the major contributors to the development of resistant organisms [2]. Although in the last years the use of antibiotics in livestock production substantially reduced (56\% over the period 2007-2012 in the Netherlands), to solve the current and future threats of multi-drug resistant organisms in (food)animals to human health, a substantial further reduction should be warranted [3]. Appropriate nutrition may aid in minimizing the incidences of diseases in livestock, among others by enhancing or improving the immune response towards these diseases [4], consequently resulting in a further reduction of the use of antibiotics. Better understanding in the nuances of nutrition and immunity is important for optimizing bird health and productivity [4]. Several studies reviewed the impact of nutritional factors on immunity, e.g. Kidd [5].

Early life gut development encompasses morphological, functional, and immunological development. After hatch, the immune system develops rapidly in broiler chickens. In the first weeks of life, different categories of immunological processes can be identified [6-8]. Based on spatio-temporal gene expression profiles, the following sequential order in time was observed for immune related processes: 1) innate development and influx of immune cells to the gut from the lymphoid tissues; 2) immune differentiation and specialization; and 3) maturation and immune regulation. Studies in pigs and laying hens showed that perturbation of the intestinal microbial colonization during early life led to altered microbiota composition and diversity in later life [9-12]. This perturbation also affected the expression of numerous immune related genes in the gut mucosal tissue for a longer period of time. This suggests an important role of the early microbial colonizers of the gut for the development and/or programming of the mucosal immune system. In addition, also studies in mice and humans show that modulating the microbial colonization in early life by antibiotics can lead to higher risk of developing immunity based disorders such as asthma and allergy [13-15]. These examples in different animal species show the importance to also investigate the impact of early life microbial colonization on the immune status in broiler chickens. Improving the immune competence of broiler chickens might contribute to their health status, and to a further reduction in the use of antibiotics.

The current study, however, focussed particularly on the impact of nutritional interventions in early life on immune competence, which is defined as the ability of the immune system to respond adequately to an antigenic stimulus, i.e. inducing an appropriate immune response with a balance between tolerance and inflammation [16]. In this study, immune competence related parameters were determined in broilers provided with nutritional interventions, e.g. amoxicillin, rye, beta-glucans, and coated butyrate, during the first week of life, followed by a Necrotic enteritis (NE) challenge in the second week of life. The reasons for selecting these interventions are explained below. NE is a multifactorial disease process, in which a number of co-factors are usually required to precipitate an outbreak of the disease. Although, $\mathrm{C}$. perfringens has been identified as the etiological agent of the disease, the predisposing factors that lead to over-proliferation of $\mathrm{C}$. perfringens and the subsequent progression to disease are poorly understood [17]. NE has been the most significant threat for the poultry industry, which, in clinical form, causes high mortality and in subclinical forms, affects growth and feed conversion.

\subsection{Feed interventions}

\subsubsection{Positive and negative control}

A positive and negative control treatment (control diet, with and without NE challenge) allowed to distinguish the effect of the NE challenge as such (positive control) from the effect of an NE challenge combined with a nutritional intervention. 


\subsubsection{Antibiotics (amoxicillin - drinking water)}

An antibiotic treatment at early age might impact the immune competence of broiler chickens. It was shown that young broiler chickens treated with enrofloxacine, florfenicol, or ceftiofur had reduced proportions of immune cells in the spleen, which might have an impact on the immune response to bacterial endotoxins in chicks [18]. Amoxicillin is used in broiler production systems to treat respiratory and gastro-intestinal infections. It is a moderate-spectrum $\beta$-lactam antibiotic and has proven effects on susceptible Gram-positive and Gram-negative bacteria [19]. In the current study, amoxicillin was used as antibiotic treatment, aiming to negatively influence the gut development at early age. The antibiotic was provided in the drinking water.

\subsubsection{Rye (25\%)}

A high dietary inclusion level of rye was chosen due to the presence of soluble non-starch polysaccharides (NSP), particularly arabinoxylans, which are complex cell wall polysaccharides, being composed of two pentose sugars, arabinose, and xylose in a branched structure [20]. Arabinoxylans create a viscous environment within the intestinal lumen [20, 21]. Increased viscosity might impair digestibility and absorption of dietary nutrients, leading to a lowered growth rate and feed conversion ratio (FCR) $[22,23]$. Dietary fibre may increase the secretion of mucus, which is produced by goblet cells [24]. Feeding rats various gelling agents increased the proliferation rate of the enterocytes of the jejunum and distal ileum, and decreased the activity of specific epithelial surface enzymes [25]. Smits and Annison (1996) hypothesized that an increased viscosity of the ileal digesta might change the morphology of the villi. Moreover, these authors emphasized that the microbiota may, at least partially, be indirectly responsible for the detrimental effects of viscous digesta. Based on observations in caecectomized broiler chickens, Choct et al. [26] concluded that the anti-nutritive effects of these pentosans in poultry are partially due to an increased activity of hindgut microbiota. Van der Klis and Van Voorst [27] reported that carboxymethyl cellulose increased the average retention time of digesta in the gastrointestinal tract, thereby giving the microbiota more time and more substrate to colonize the proximal small intestine. Feeding broiler chickens a wheat/rye-based diet, high in NSP, seriously decreased immunity-related parameters of the chickens. This has been indicated by induced villus fusion, reduced thickness of the tunica muscularis, induced T-lymphocyte infiltration, more and larger goblet cells, more apoptosis of epithelial cells in the mucosa, and a shift in microbiota [28]. Smits and Annison (1996) hypothesized that an increased viscosity of the ileal digesta, due to the presence of soluble NSP, might change the morphology of the villi. These NSP, when present at the surface of or within the mucus layer, may serve as substrate for microbial growth and may stimulate bacterial proliferation and attachment of bacteria to the mucins and glycocalix. Subsequently, some bacterial species, e.g. Streptococcus faecium, may cause atrophy of the villi [29, 30].

Based on the available literature, it was hypothesized that dietary inclusion of rye would increase viscosity of intestinal digesta, consequently resulting in an effect on nutrient absorption, gut wall morphology, composition of microbiota, and immune-related processes in the gut wall. Therefore, it was expected that rye in grower diets of broilers might be a helpful model ingredient to investigate the negative effects of nutrition on immune competence related parameters. In the current study, $25 \%$ rye was included in the diet (Note: that this was not a 1:1 exchange of wheat and rye). To maintain a high viscosity in jejunum and ileum, animal fat was used as the primary fat source instead of soya oil [31]. 
Saccharomyces cerevisiae, on activation of the transcription factors activator protein- 1 and specificity protein- 1 in normal human dermal fibroblasts. These authors showed that $\beta$-glucan stimulated fibroblast expression of neurotrophin 3, platelet derived growth factor A, platelet derived growth factor $B$, fibroblast growth factor acidic, fibroblast growth factor basic, transforming growth factor alpha, transforming growth factor beta, and vascular endothelial growth factor mRNA, all involved in wound healing. Wound healing is an immune mediated event [45], and agents which modulate the innate immune response might also contribute to the modulation of wound healing process [46-48]. In addition, Delatte et al. [49] reported that paediatric burns could effectively be treated with glucancollagen mixtures. In another study, $(1,3 / 1,6)$ - $\beta$-D-glucan affected lung immune development in the neonatal piglet because of a reduced mRNA expression of transforming growth factor (TGF) $\beta 2$, and a trend to a reduced mRNA expression of TGF- $\beta 1$ in lung tissue [50]. Thus, the effects of dietary $\beta$ glucans on immune responses can be mediated via regulating activities of growth factors. In the current study, the effect of dietary supplementation of $2 \mathrm{~g} / \mathrm{kg}$ of $\beta$-glucans (85\% pure product; Wellmune) to the starter diet on immune related parameters was investigated.

\subsubsection{Butyrate}

Dietary butyrate supplementation has been shown to improve growth performance and resilience of broiler chickens through distinct mechanisms operating on both eukaryotic and prokaryotic cells. Inconsistent effects of butyrate supplementation on performance have been reported, however, which seem to be partly explained by health status of the animal, diet composition, environmental conditions, coated versus uncoated butyrate and coating matrix, and the butyrate inclusion level [51]. Inconsistent effects of dietary butyrate supplementation on for example broiler gut integrity are reported, as reviewed by Moquet [52]. Firstly, butyrate influences endogenous avian cells in multiple ways: it functions as an agonist of free-fatty acid receptors and an inhibitor of pro-inflammatory pathways [53,54]. Feeding $1 \mathrm{~g} / \mathrm{kg}$ of unprotected butyrate to broiler chicken resulted in a significant increase in expression of genes encoding for antimicrobial peptides, which could subsequently induce chemotaxis of avian innate immune cells [55]. Butyrate can prevent inflammation and infiltration of immune cells in peripheral tissues by influencing cell adhesion and chemotaxis [56]. Broiler chickens that were provided $1 \mathrm{~g} / \mathrm{kg}$ unprotected butyrate had reduced serum TNF- $\mathrm{a}$ and IL- 6 levels at $21 \mathrm{~d}$ of age, while serum antioxidant indices were increased [57]. Moreover, butyrate influences the microbiota residing in the avian gastrointestinal tract (GIT) as a result of its bacteriostatic properties. In the current study, the effect of dietary supplementation of $0,417 \%$ Adimix Precision to realize a dosage of $0.1 \%$ pure butyrate to the starter diet on immune-related parameters was investigated.

\subsection{Objective}

The objective of this study was to determine the effect of nutritional interventions with amoxicillin, rye, beta-glucans, or coated butyrate, provided during the first week of life, before they were challenged by the Necrotic enteritis model, on performance and immune competence related parameters of broiler chickens. A positive and negative control treatment (challenged vs. unchallenged broilers) was included to estimate the effect of the NE challenge. In addition, we want to correlate these changes in immune competence related parameters to the quantitative disease phenotype of broilers during their second week of life. 


\section{$2 \quad$ Materials and Methods}

\section{$2.1 \quad$ Experimental design}

The study consisted of 6 treatments (Table 1). One control treatment ("negative control") received no challenge, whereas the remaining five treatments received a NE challenge after the period where they received a (nutritional) intervention. Chickens received an experimental pre-starter diet during the first week of life. Afterwards, all pens received a common starter diet until $16 \mathrm{~d}$ of age and a common grower diet until $35 \mathrm{~d}$ of age. Treatments were randomly distributed over 12 blocks (divided over two rooms) into 72 pens, resulting in 12 replicates per treatment with 15 chickens each.

Table 1. Experimental design

\begin{tabular}{cccc} 
Treatment & Description & NE Challenge & Inclusion level \\
Unchallenged control & Control & No & - \\
Challenged control & Control & Yes & - \\
ANT & Antibiotic (amoxicillin) & Yes & $20 \mathrm{mg} / \mathrm{kg} \mathrm{BW} / \mathrm{day}$ \\
RYE & Rye & Yes & $25 \%$ \\
BG & Beta-glucans & Yes & $0.2 \%$ \\
BUTY & Butyrate & Yes & $0.1 \%{ }^{1}$ \\
\hline
\end{tabular}

${ }^{1}$ Pure butyrate.

\subsection{Animal experiment}

\subsubsection{Animal housing and management}

One thousand and eighty Ross 308 male day-old chickens, derived from a 36-week old broiler breeder flock, were purchased from a commercial hatchery (Lunteren, the Netherlands) and randomly allocated across 72 pens. Each pen consisted of 15 chickens with an initial individual BW of $39.6 \pm 0.8$ (g). Pen sizes were in accordance with housing requirements as stated in Annex III of the 2010 / 63 / EU Directive and had a raised floor covered with a $2-\mathrm{cm}$ layer of wood shavings. In total, there were 12 pens per treatment; 6 pens in each room. Each pen was equipped with nipple drinkers (adjustable in height) and a feeder that was positioned inside the pen for the first $14 \mathrm{~d}$ of age. From $14 \mathrm{~d}$ onwards, feed was supplied via a feeder trough in front of the pen.

Throughout the study, a strict hygiene protocol was maintained and access was restricted (shower-in, shower-out, and change of clothes) due to the applied NE challenge. Chickens were kept until $35 \mathrm{~d}$ of age and had ad libitum access to water and feed, except in advance of inoculation and lesion scoring (related to NE challenge). I mmediately after inoculation, chickens were provided feed access again. The light schedule and climate settings used were in line with practice (Directive 2007 / 43 / EC). Chickens were spray-vaccinated against Newcastle Disease (Poulvac NDW-vaccine, Zoetis Inc., NJ) at $18 \mathrm{~d}$ of age.

\subsubsection{NE challenge}

To facilitate successful colonization of Clostridium perfringens in the small intestine, broiler chickens were first inoculated with a $1 \mathrm{ml}$ inoculant containing Eimeria maxima $(\sim 4,500$ sporulated oocyst/ml) at $7 \mathrm{~d}$ of age. Next, broiler chickens were inoculated with a $1 \mathrm{ml}$ inoculant containing $\mathrm{C}$. perfringens $\left(\sim 1 \times 10^{8} \mathrm{cfu} / \mathrm{ml}\right)$ at $13 \mathrm{~d}$ of age. In advance of inoculation at 7 and $13 \mathrm{~d}$ of age, chickens were feed deprived for about 5 hours. The E. maxima and C. perfringens were both obtained from the GD Animal Health (Deventer, the Netherlands) and were orally inoculated using a 1 cc syringe without needle. Broiler chickens from the control treatment that was not challenged, received a sterilized inoculum. 
The purpose of the challenge was to influence growth performance without increasing mortality, resulting in a sub-clinical NE challenge.

At 14 and $15 \mathrm{~d}$ of age, 2 randomly selected broiler chickens per pen were selected for intestinal postmortem lesion scores related to the E. maxima and C. perfringens. Birds were euthanized with an intermuscular administration of Zoletil (30 mg/kg; Virbac, Barneveld, the Netherlands) and subsequently bled. Lesion scores for E. maxima, characterized by haemorrhages, blood and orange mucus, were conducted in the second loop of the duodenum and jejunum until the Meckels diverticulum and ranged from $0-4,0=$ no haemorrhages, $1=$ One or some haemorrhages, $2=$ Several haemorrhages, 3= Many haemorrhages, orange mucus in the lumen, 4= Many haemorrhages, mucosal damage (free blood in the lumen). Lesion scores for C. perfringens, characterized by white, brown, or grey spots, were conducted from the gizzard towards Meckels diverticulum and ranged from $0-4,0=$ no lesions, $1=$ One to five lesion present in the intestine, $2=$ More than 5 single distinguished lesions, $3=$ Lesions merge or extend to a surface of more than $1 \mathrm{~cm}^{2}, 4=$ Pseudo membranes present in the intestine causing death. All chickens were scored by the same veterinarian (GD Animal Health, Deventer, the Netherlands) with solid expertise in distinguishing the different lesions types and lesion severities.

\subsubsection{Diets and nutritional interventions}

In advance of diet formulation, batches of corn, wheat, soybean meal, toasted soybeans, and rye were reserved and analysed. For each feeding phase (pre-starter, starter, grower) diets were formulated. Diet formulations were derived from a previous study focusing on the effects of rye inclusion on immunity related parameters and performance (Wageningen UR Livestock report 889; project B031.03-005-001 Feed4Foodure).

For rye, no $M E_{\text {broiler }}$ value was defined in the CVB Feed Tables. Therefore, the $\mathrm{ME}_{\text {broiler }}$ value for rye was calculated by deriving digestibility coefficients for crude protein (CP), crude fat (CFat), and nitrogen free extract (NFE) from the digestibility coefficients for rye in older birds, using similar analogy as for wheat. For wheat, the digestibility coefficients of CP, CFat, and NFE were $0.81,0.60$, and 0.90 for poultry, and $0.83,0.53$, and 0.84 for broiler chickens, respectively. As such, absolute differences in digestibility coefficients between poultry and broiler chickens were $+0.02,-0.07$, and -0.06 ,

respectively. For rye, digestibility coefficients of crude protein, crude fat and NFE were $0.60,0.31$, and 0.82 for poultry, thus resulting in $0.62,0.25$, and 0.76 for broiler chickens. Using dCP, dCFat and NFE values of 93,17 and $708 \mathrm{~g} / \mathrm{kg}$, respectively, the calculated $\mathrm{ME}_{\text {broiler }}$ for rye was $2482 \mathrm{kcal} / \mathrm{kg}$. Inclusion of rye was at the expense of wheat, while keeping the diets isocaloric. For the rye diet, animal fat was used as the primary fat source instead of soybean oil.

Butyrate was added at the expense of an inert filler (Diamol, Ligrana, Germany). A correction was made for the dietary sodium level by exchanging with sodium bicarbonate. Butyrate was dosed based on the intended pure butyrate level (0.1\%). Adimix Precision (Nutriad, Belgium) contains $30 \%$ sodium butyrate, of which $6 \%$ is sodium. I.e. the actual butyrate level in Adimix Precision was $24 \%$.

Therefore, Adimix Precision was included at $0.417 \%$ to dose $0.1 \%$ pure butyrate.

Beta-glucans (85\% pure product; Wellmune, United States) was added at the expense of an inert filler (Diamol, Ligrana, Germany) at $0.2 \%$.

Pre-starter diets were manufactured using one basal diet. Diets were produced by Research Diet Services (RDS, the Netherlands) and pelleted at $2.5 \mathrm{~mm}$ (pre-starter), $2.5 \mathrm{~mm}$ (starter), and $3.0 \mathrm{~mm}$ (grower diet). Composition of the experimental diets is given in Table 2.

In addition to the control diet, broiler chickens of treatment 3 received an antibiotic (Octacillin; Dechra, the Netherlands) dissolved in water during the first week of life. The following assumptions were made for dosing calculations: 1) Intended dose of $20.0 \mathrm{mg}$ amoxicillin per $\mathrm{kg}$ BW per day, 2) Octacillin (product name) contains $697 \mathrm{mg}$ amoxicillin per gram of product, and 3) Octacillin dose: $28.7 \mathrm{mg}$ per $\mathrm{kg} \mathrm{BW}$ per day. Average bodyweight and average water intake were used to calculate the dosing of the Octacillin on a daily basis. Every morning a new solution (drinking water + Octacillin) was made for the pens receiving the antibiotic treatment. From day 3 until day 7, a calculation error resulted in double dosing of Octacillin from what was intended. 
Table 2. Composition of the experimental diets

\begin{tabular}{|c|c|c|c|c|c|c|c|}
\hline Diet code & & 1 & 4 & 5 & 6 & 7 & 8 \\
\hline Treatment & & $1-3$ & 4 & 5 & 6 & $1-6$ & $1-6$ \\
\hline Phase & & $0-7 d$ & $0-7 \mathrm{~d}$ & $0-7 \mathrm{~d}$ & $0-7 d$ & $7-16 \mathrm{~d}$ & $16-35 d$ \\
\hline \multicolumn{8}{|c|}{ Ingredient composition, \% } \\
\hline Maize & & 29.7 & 26.8 & 29.7 & 29.7 & 40.6 & 42.8 \\
\hline Wheat & & 25.0 & - & 25.0 & 25.0 & 15.0 & 15.0 \\
\hline Rye & & - & 25.0 & - & - & - & - \\
\hline Soybean meal HP & & 33.6 & 33.8 & 33.6 & 33.6 & 35.0 & 32.8 \\
\hline Toasted soybeans & & 2.00 & 2.00 & 2.00 & 2.00 & - & - \\
\hline Animal fat & & 1.00 & 6.18 & 1.00 & 1.00 & 1.50 & 1.50 \\
\hline Soybean oil & & 3.51 & 1.00 & 3.51 & 3.51 & 3.67 & 4.21 \\
\hline Monocalcium phosphate & & 1.40 & 1.37 & 1.40 & 1.40 & 1.20 & 0.92 \\
\hline Limestone & & 1.36 & 1.38 & 1.36 & 1.36 & 1.32 & 1.06 \\
\hline Salt & & 0.27 & 0.25 & 0.27 & 0.27 & 0.30 & 0.30 \\
\hline Sodium bicarbonate & & 0.16 & 0.16 & 0.06 & 0.16 & 0.11 & 0.11 \\
\hline DL-Methionine & & 0.27 & 0.30 & 0.27 & 0.27 & 0.20 & 0.18 \\
\hline L-Lysine HCL & & 0.17 & 0.18 & 0.17 & 0.17 & 0.05 & 0.06 \\
\hline L-Threonine & & 0.07 & 0.09 & 0.07 & 0.07 & - & - \\
\hline L-Valine & & 0.04 & 0.07 & 0.04 & 0.04 & - & - \\
\hline DIAMOL & & 0.50 & 0.50 & 0.18 & 0.30 & - & - \\
\hline Adimix Precision & & - & - & 0.42 & - & - & - \\
\hline Beta glucans & & - & - & - & 0.20 & - & - \\
\hline Premix broilers starter ${ }^{1}$ & & 1.00 & 1.00 & 1.00 & 1.00 & 1.00 & - \\
\hline Premix broilers grower ${ }^{2}$ & & - & - & - & - & - & 1.00 \\
\hline Total & & 100.0 & 100.0 & 100.0 & 100.0 & 100.0 & 100.0 \\
\hline Crude protein & $\%$ & 22.3 & 22.0 & 22.3 & 22.3 & 21.9 & 21.0 \\
\hline Crude fat & $\%$ & 6.6 & 9.2 & 6.6 & 6.6 & 7.1 & 7.7 \\
\hline Crude fibre & $\%$ & 2.7 & 2.6 & 2.7 & 2.7 & 2.6 & 2.6 \\
\hline Calcium & $\%$ & 0.90 & 0.90 & 0.90 & 0.90 & 0.85 & 0.70 \\
\hline Phosphorous P & $\%$ & 0.71 & 0.71 & 0.71 & 0.71 & 0.66 & 0.59 \\
\hline Sodium & $\%$ & 0.16 & 0.16 & 0.16 & 0.16 & 0.16 & 0.16 \\
\hline Potassium & $\%$ & 1.00 & 1.00 & 1.00 & 1.00 & 1.00 & 0.95 \\
\hline Chloride & $\%$ & 0.23 & 0.23 & 0.23 & 0.23 & 0.23 & 0.23 \\
\hline Dig P & $\%$ & 0.42 & 0.42 & 0.42 & 0.42 & 0.38 & 0.32 \\
\hline ME broiler & kcal & 2800 & 2800 & 2800 & 2800 & 2875 & 2950 \\
\hline dig. Lysine & $\%$ & 1.15 & 1.15 & 1.15 & 1.15 & 1.05 & 1.00 \\
\hline dig. Methionine & $\%$ & 0.55 & 0.57 & 0.55 & 0.55 & 0.48 & 0.45 \\
\hline dig. Met.+Cys. & $\%$ & 0.84 & 0.84 & 0.84 & 0.84 & 0.77 & 0.73 \\
\hline dig. Threonine & $\%$ & 0.75 & 0.75 & 0.75 & 0.75 & 0.68 & 0.65 \\
\hline dig. Tryptophan & $\%$ & 0.23 & 0.22 & 0.23 & 0.23 & 0.23 & 0.22 \\
\hline dig. Isoleucine & $\%$ & 0.82 & 0.79 & 0.82 & 0.82 & 0.82 & 0.78 \\
\hline dig. Valine & $\%$ & 0.92 & 0.92 & 0.92 & 0.92 & 0.88 & 0.85 \\
\hline dig. Arginine & $\%$ & 1.33 & 1.29 & 1.33 & 1.33 & 1.32 & 1.26 \\
\hline C18:2 (Linoleic acid) & $\%$ & 2.87 & 2.02 & 2.87 & 2.87 & 2.90 & 3.20 \\
\hline
\end{tabular}

${ }^{1}$ Contributed per kilogram of diet: thiamine, $1.0 \mathrm{mg}$; riboflavin, $4.5 \mathrm{mg}$; niacinamide, $40 \mathrm{mg}$; D-pantothenic acid, $9 \mathrm{mg}$; pyridoxine-HCL, $2.7 \mathrm{mg}$; choline chloride, $500 \mathrm{mg}$; cyanocobalamin, $20 \mu \mathrm{g}$; vitamin E (DL-atocopherol), $33 \mathrm{IU}$; menadione, $2.3 \mathrm{mg}$; vitamin A (retinyl-acetate), 12,000 IU; cholecalciferol, 5,000 IU; biotin, $100 \mu \mathrm{g}$; folic acid, $0.5 \mathrm{mg}$; FeSO4.H2O, $150 \mathrm{mg}$; MnO2, $100 \mathrm{mg}$; CuSO4.5H2O, $40 \mathrm{mg}$; ZnSo4.H2O, $145 \mathrm{mg}$; Na2SeO3, $0.56 \mathrm{mg}$; KI, $2.0 \mathrm{mg}$; antioxidant (oxytrap PXN), $125 \mathrm{mg}$.

${ }^{2}$ Contributed per kilogram of diet: thiamine, $0.8 \mathrm{mg}$; riboflavin, $4.5 \mathrm{mg}$; niacinamide, $30 \mathrm{mg}$; D-pantothenic acid, $8 \mathrm{mg}$; pyridoxine- $\mathrm{HCL}, 1.9 \mathrm{mg}$; choline chloride, $400 \mathrm{mg}$; cyanocobalamin, $20 \mu \mathrm{g}$; vitamin E (DL-atocopherol), $22 \mathrm{IU}$; menadione, $2.3 \mathrm{mg}$; vitamin A (retinyl-acetate), 10,000 IU; cholecalciferol, 2,000 IU; biotin, $50 \mu \mathrm{g}$; folic acid, $0.5 \mathrm{mg}$; FeSO4.H2O, $150 \mathrm{mg}$; MnO2, $100 \mathrm{mg}$; CuSO4.5H2O, $40 \mathrm{mg}$; ZnSo4.H2O, $145 \mathrm{mg}$; Na2SeO3, $0.50 \mathrm{mg}$; KI, $1.9 \mathrm{mg}$; antioxidant (oxytrap PXN), $125 \mathrm{mg}$.

\subsubsection{Performance and sampling}

Group weights were recorded at start of the experiment (day 0), whereas individual body weights were recorded at $7,13,16,21,28$ and $35 \mathrm{~d}$ of age. In addition, feed consumption for each pen was recorded on the same day the chickens were weighed. Based on body weight and feed consumption, the average daily gain (ADG; grams per day), average daily feed intake (ADFI; grams per day), and gain to feed ratio (G:F; kg of weight gain / kg of feed consumed) were calculated. Total feed consumption per pen was corrected for mortality, removal and outliers. On 7, 14, and $35 \mathrm{~d}$ of age, two chicks per pen were sacrificed in order to obtain tissue samples to investigate immunological and histological parameters. 


\subsection{Analysis of microbiota composition}

\subsubsection{DNA isolation}

Microbiota composition was determined of broiler digesta from jejunum, ileum and colon. Samples were frozen on dry-ice after collection and stored at $-80^{\circ} \mathrm{C}$. To isolate DNA, samples were mixed in a 1: 1 ratio with phosphate buffered saline (PBS) and centrifuged for $5 \mathrm{~min}$ at $4^{\circ} \mathrm{C}$ at $300 \mathrm{xg}$. Supernatant was collected and centrifuged for $10 \mathrm{~min}$ at $4^{\circ} \mathrm{C}$ at 9,000xg. DNA was extracted from the pellet using the "QI Aamp FAST DNA stool minikit" according to manufacturers' instructions. Quality and quantity of DNA was checked using the NANOdrop (Agilent Technologies, CA, United States).

\subsubsection{Sequence analyses of 16S rDNA}

PCR was used to amplify the 16S rDNA V3/V4 fragment using forward primer V3_F (CCTACGGGAGGCAGCAG) and reverse primer V4_R (GGACTACHVGGGTWTCT). PCR conditions were as follows: $2 \mathrm{~min}$ at $98^{\circ} \mathrm{C}, 15 \times\left(10 \mathrm{~s}\right.$ at $98^{\circ} \mathrm{C}, 30 \mathrm{~s}$ at $55^{\circ} \mathrm{C}, 10 \mathrm{~s}$ at $\left.72^{\circ} \mathrm{C}\right), 7 \mathrm{~min}$ at $72^{\circ} \mathrm{C}$. PCR efficiency was checked on agarose gel by visual inspection. Samples were sequenced by targetedamplicon 16S sequencing using the MiSeq sequencer (Illumina, CA, United States) and analysed for taxonomy profile per sample with clustering by profile by using QIIME [58]. Standard assembly based on amplicons was performed after removal of primer sequences. Data was filtered to yield high quality sequence data using the following settings: 1) > Q20 and 2) amplicons >100 bases. For the data analysis pseudoreads were clustered into operational taxonomic units (OTUs) per sample at $97 \%$ similarity and OTU-representative sequences were aligned against the aligned Greengenes core set (13_8 release) [59, 60]. Furthermore chimeras were removed with Chimeraslayer [61].

\subsection{Gene expression of intestinal tissue}

\subsubsection{RNA isolation}

Total RNA was extracted from 50 to $100 \mathrm{mg}$ of mucosal mid-jejunum tissue. Samples were homogenised using the TissuePrep Homogenizer Omni TP TH220P in $5 \mathrm{ml}$ TRI zol reagent (Life Technologies, CA, United States). The homogenate was centrifuged for $5 \mathrm{~min}$ at 21,000 xg. $350 \mu \mathrm{l}$ of supernatant was used to isolate RNA using the Direct-zol kit (Zymo Research, CA, United States) according to instructions of the manufacturer. Quality control was performed on the BioAnalyser (Agilent Technologies, CA, United States), quantity of RNA was determined using the Tape station (Agilent 2200 tape station, Agilent technologies, CA, United States).

\subsubsection{Microarrays: Labelling and hybridization procedure}

Labelling of RNA was done as recommended by Agilent Technologies using the One-Color MicroarrayBased Gene Expression Analysis Low input Quick Amp Labelling. 200 ng of total RNA was used as input, $600 \mathrm{ng}$ of labelled cRNA was used to hybridise the porcine microarray (Agilent Technologies, CA, United States). Hybridisation was performed at $65^{\circ} \mathrm{C}$ for $17 \mathrm{~h}$ with head-over-head rotation. Microarrays were washed as recommended by the manufacturer. Microarrays were scanned using the Surescan high resolution scanner (Agilent Technologies, CA, United States) at a resolution of $3 \mu \mathrm{m}, 20$ bits and PMT of $100 \%$. Feature extraction was performed using protocol 10.7.3.1 (v10.7) for 1 colour gene expression.

\subsection{Histology}

\subsubsection{Morphometric measurements}

Formalin fixed samples were embedded in paraffin, sectioned at $5 \mu \mathrm{m}$, and stained with hematoxylin and eosin for histologic examination. Villus length, crypt depth and mucosa length were determined using I mage-Pro Plus software v7.0.1 (Media Cybernetics, MD, USA). In Appendix A, an example 
microscopic image is given accompanied by the measurements. Per animal ten crypts and their ten associated villi were measured.

\subsubsection{Periodic acid-Schiff / alcian blue staining (goblet cells)}

This is a combined method utilising the properties of both the periodic acid-Schiff (PAS) and alcian blue methods to demonstrate the full complement of tissue proteoglycans. The rationale of the technique is that by first staining all the acidic mucins with alcian blue, those remaining acidic mucins which are also PAS positive will be chemically blocked and will not react further during the technique. Those neutral mucins which are solely PAS positive will subsequently be demonstrated in a contrasting manner. Where mixtures occur, the resultant colour will depend upon the dominant moiety.

\subsection{Statistical analyses}

\subsubsection{Performance data, lesion scores, mortality}

For comparison of the different treatments, all data were subjected to mixed model analysis using the PROC Glimmix procedure in SAS (Version 9.3, 2011, SAS Institute Inc., NC, United States) according to the following statistical model:

$$
Y_{i j}=\mu+a_{i}+b_{j}+\varepsilon_{i j}
$$

where:

$\mathrm{Y}_{\mathrm{ij}} \quad=$ a specific trait per experimental unit

$\mu \quad=$ overall mean

$\mathrm{a}_{\mathrm{i}} \quad=$ fixed effect of dietary treatment fat level $(i=1-6)$

$b_{j} \quad=$ random block effect $(j=A-L)$

$\varepsilon_{\mathrm{ij}} \quad=$ error term

Lesion scores were analysed as ordinal data and mortality as binomial data, using the PROC GLIMMIX procedure in SAS and the same model parameters used as for performance data. For lesion scores, results are presented as the probability of a higher lesion score.

Data are expressed as least square (LS) means \pm SEM. LSmeans were compared after being corrected with a Tukey test for multiple comparisons and effects were considered to be significant when $P \leq 0.05$.

\subsubsection{Microbiota data}

The biodiversity of the microbiota was calculated by the vegan package http://cran.rproject.org/web/packages/vegan/ within the R environment ( $R$ v3.0.2), by employing the Shannon diversity indices, as well as species and evenness. The Redundancy analysis (RDA) was also performed by using the vegan package. The following model was used on the family level microbiota data: $Y=$ Time (day) + Treatment + error. Furthermore, statistical significance testing for over- and underrepresentation of the bacterial groups was made at the phylum / family / species level by performing the Wilcoxon signed-rank test, and P-values were also converted to false discovery rate (FDR) values to correct for multiple testing. Before day 7 of age 2 control groups exist, i.e. the unchallenged $(n=24)$ and challenged controls $(n=24)$. After quality control for jejunum samples, 19 unchallenged and 18 challenged control samples remained, 20 samples in the antibiotic group, 18 samples in the $\beta$-glucans group, 17 samples in the butyrate group, and 18 samples in the rye group. In colon, 23 unchallenged and 24 challenged control samples remained and 23 for the butyrate group.

For the semi-quantification of the microbiota, a polymerase chain reaction (PCR) was performed. With this PCR we focused on the $16 \mathrm{~S}$ gene (representing the microbiota) and the Green Fluorescent Protein (GFP), a measure for how efficient the PCR has been performed. The threshold cycle value, so called Ct value, were calculated as well as a proxy for the quantity of each gene (i.e. 16S and GFP). Lastly the ratio between $16 \mathrm{~S}$ Ct and GFP Ct, which could possibly be used to correct the average relative contributions. The latter we did not perform in this study. 


\subsubsection{Gene expression (microarray data)}

The data were analysed by using R (v3.0.2) by executing different packages, including LIMMA and arrayQualityMetrics [62]. The data were read in and background corrected (method="normexp" and offset=1) with functions from the R package LIMMA from Bioconductor [63]. Quantile normalisation of the data was performed between arrays. The duplicate probes mapping to the same gene were averaged ('avereps') and subsequently the lower percentile of probes was removed in a three-step procedure: 1) get the highest of the dark spots to get a base value, 2) multiply by $1.1,3$ ) the gene/probe had to be expressed in each of the samples in the experimental condition. To test the differences between the experimental groups, i.e. control versus treatment group), the contrasts between control and treatment group were studied for each time-point separately within the LIMMA package. Two control groups exist, i.e. the unchallenged $(n=24)$ and challenged controls $(n=22)$.

\subsubsection{Histology}

The data were analysed by using R (v3.0.2) by executing different packages, including 'aov' and 'TukeyHSD' to perform statistical testing between groups. The data were read in subsequently three separated ANOVAs were performed, for goblet cells, villi length, and crypt depth, when significant the Tukey post-hoc test was performed to identify which groups differed significantly. 


\section{Results}

\subsection{Effect of nutritional interventions on performance}

\section{Body weight}

BW at $7 \mathrm{~d}$ of age was similar for both control treatments. From $7 \mathrm{~d}$ of age onwards (after inoculation with E. Maxima at $7 \mathrm{~d}$ of age), challenged broiler chickens fed the control diet has a lower BW compared to the unchallenged broiler chickens. The difference in BW between challenged and unchallenged broiler chickens persisted throughout the study, resulting in an absolute difference in BW of $150 \mathrm{~g}$ at $35 \mathrm{~d}$ of age (Table 3 ).

Provision of diets supplemented with rye, $\beta$-glucans or butyrate during the first week of life did not affect BW at $7 \mathrm{~d}$ of age compared to the (un) challenged control treatment. On the contrary, broiler chickens that received antibiotic treatment had a higher BW at $7 \mathrm{~d}$ of age compared to all other treatments. At $13 \mathrm{~d}$ of age, BW of broiler chickens receiving the antibiotic treatment remained numerically higher than the controls or broiler chickens receiving another treatment. At 16 and $21 \mathrm{~d}$ of age (after additional inoculation with $C$. perfringens), BW of broiler chickens receiving the antibiotic treatment was higher compared to all other challenged treatments $(P<0.001$; Table 3 ). No differences in BW at $35 \mathrm{~d}$ of age were found amongst challenged broiler chickens, regardless of treatment (Table 3).

Table 3. Effect of (dietary) treatment and a necrotic enteritis (NE) challenge with inoculation of $\mathrm{E}$. maxima at $7 \mathrm{~d}$ of age and $\mathrm{C}$. perfringens at $13 \mathrm{~d}$ of age, on body weight of broiler chickens

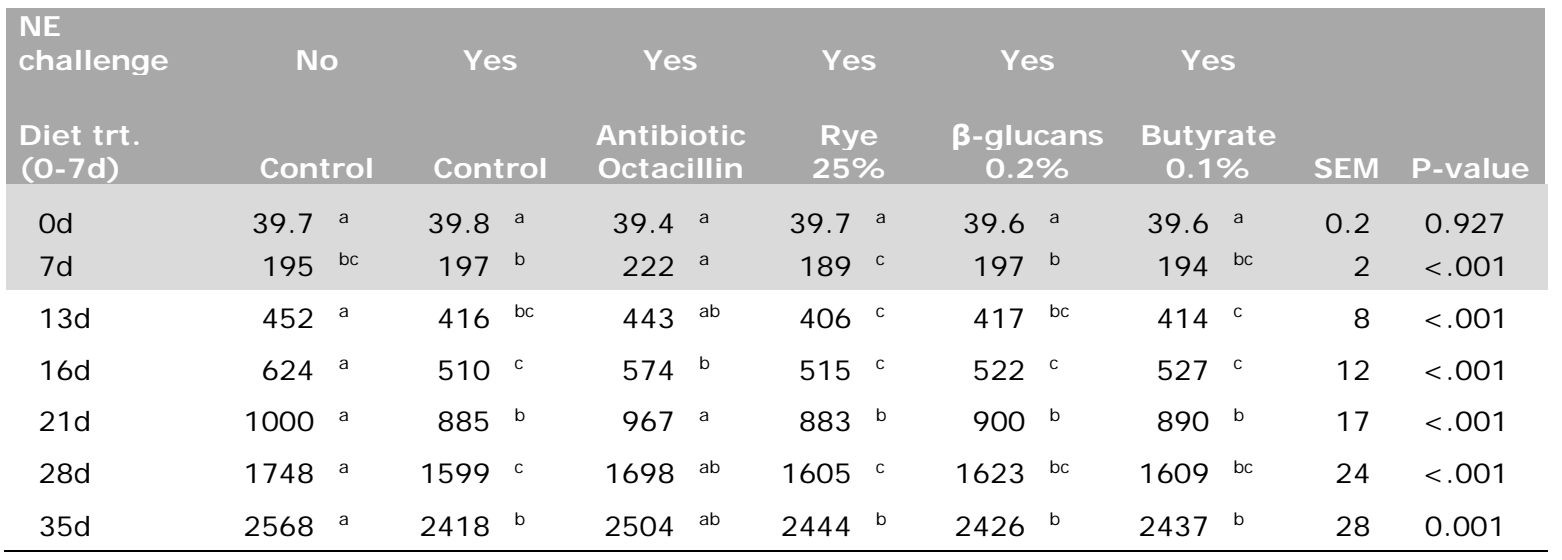

a-c LSmeans within a row lacking a common superscript differ $(P \leq 0.05)$. Note that at day 0 and 7 , the challenged birds were not yet challenged (highlighted in grey).

\section{Performance 0 to $7 \mathrm{~d}$ of age: Provision of (dietary) treatments}

From 0 to $7 \mathrm{~d}$ of age, provision of an antibiotic in the drinking water resulted in a higher ADG (25.8 $\mathrm{g} / \mathrm{d}$ ) and ADFI $(23.4 \mathrm{~g} / \mathrm{d})$ compared to all other treatments $(P<0.001$; Table 4). Rye inclusion resulted in the lowest ADG. Provision of an antibiotic in the drinking water resulted in the highest $G$ : $F$ ratio (1.102), rye inclusion for the lowest (1.059; $P=0.004$; Table 4).

\section{Performance 7 to $16 \mathrm{~d}$ of age: Necrotic enteritis challenge}

From 7 to $13 \mathrm{~d}$ of age, after inoculation with E. maxima, the non-challenged control treatment had a higher ADG (43 g/d), ADFI ( $52 \mathrm{~g} / \mathrm{d}$ ) and G:F ratio (0.83) compared to the challenged control (ADG 37 g/d, ADFI $48 \mathrm{~g} / \mathrm{d}$, G:F ratio 0.757; P<0.05; Table 4). 
From 13 to $16 \mathrm{~d}$ of age, after inoculation with $\mathrm{C}$. perfringens, the non-challenged control treatment had higher ADG (58.8 g/d), ADFI $(72.9 \mathrm{~g} / \mathrm{d})$, and G: F ratio $(0.81)$ compared to the challenged control (ADG $34 \mathrm{~g} / \mathrm{d}$, ADFI $56 \mathrm{~g} / \mathrm{d}$, and G:F ratio 0.60; P<0.001; Table 4). Amongst the challenged treatments, $A D G$ and ADFI of broiler chickens that received the antibiotic treatment were higher than the challenged control treatment ( 41.6 and $62.1 \mathrm{~g} / \mathrm{d}$ vs. 29.3 and $53.5 \mathrm{~g} / \mathrm{d}$; P<0.001; Table 4). The other treatments showed intermediate results.

Throughout the challenge period ( 7 to $16 \mathrm{~d}$ of age), the non-challenged control treatment had a higher ADG, ADFI, and G:F ratio compared to the challenged control. No differences in performance were observed amongst dietary treatments $(P<0.001$; Table 4$)$.

Table 4. Effect of (dietary) treatment and a necrotic enteritis (NE) challenge with inoculation of $E$. maxima at $7 \mathrm{~d}$ of age and $C$. perfringens at $13 \mathrm{~d}$ of age on performance parameters (ADG, ADFI, and $\mathrm{G}: \mathrm{F})$

\begin{tabular}{|c|c|c|c|c|c|c|c|c|c|c|c|c|c|c|}
\hline \multirow{2}{*}{$\begin{array}{l}N^{1} \\
\text { challenge } \\
\text { Treatment } \\
(0-7 d) \\
\text { ADG }^{2} 0-7 d\end{array}$} & \multicolumn{2}{|l|}{ No } & \multicolumn{2}{|l|}{ Yes } & $\begin{array}{l}\text { Antibiotic } \\
\text { Octacillin }\end{array}$ & Yes & $\begin{array}{l}\text { Rye } \\
25 \%\end{array}$ & & $\begin{array}{c}\beta \text {-glucan } \\
0.2 \%\end{array}$ & an & \multicolumn{2}{|c|}{$\begin{array}{c}\text { Butyrate } \\
0.1 \%\end{array}$} & SEM & P-value \\
\hline & 22.2 & $\mathrm{bc}$ & 22.4 & $\mathrm{~b}$ & 25.8 & a & 21.1 & c & 22.4 & b & 22.0 & $\mathrm{bc}$ & 0.3 & $<.001$ \\
\hline $\mathrm{ADFI}^{3} 0-7 d$ & 20.5 & $\mathrm{~b}$ & 20.6 & $\mathrm{~b}$ & 23.4 & a & 19.9 & $\mathrm{~b}$ & 20.8 & $\mathrm{~b}$ & 20.3 & $\mathrm{~b}$ & 0.3 & $<.001$ \\
\hline$G: F^{4} 0-7 d$ & 1.083 & $a b$ & 1.086 & $a b$ & 1.102 & a & 1.059 & $\mathrm{~b}$ & 1.081 & $a b$ & 1.084 & $a b$ & 0.007 & 0.004 \\
\hline ADG 7-13d & 43.1 & a & 36.3 & b & 36.6 & $\mathrm{~b}$ & 36.3 & $\mathrm{~b}$ & 36.8 & b & 36.6 & $\mathrm{~b}$ & 1.1 & $<.001$ \\
\hline ADFI 7-13d & 51.8 & a & 48.0 & b & 49.1 & $a b$ & 47.8 & $\mathrm{~b}$ & 48.3 & $\mathrm{~b}$ & 47.8 & $b$ & 0.8 & 0.002 \\
\hline G:F 7-13d & 0.831 & a & 0.757 & b & 0.744 & b & 0.758 & $\mathrm{~b}$ & 0.760 & $\mathrm{~b}$ & 0.765 & b & 0.013 & $<.001$ \\
\hline $\begin{array}{l}\text { ADG 13- } \\
16 d\end{array}$ & 58.8 & a & 29.3 & c & 41.6 & $\mathrm{~b}$ & 33.2 & bc & 32.0 & bc & 34.0 & bc & 2.7 & $<.001$ \\
\hline $\begin{array}{l}\text { ADFI 13- } \\
16 d\end{array}$ & 72.9 & a & 53.5 & c & 62.1 & $\mathrm{~b}$ & 56.9 & bc & 54.1 & $\mathrm{bc}$ & 54.4 & $\mathrm{bc}$ & 2.0 & $<.001$ \\
\hline G:F 13-16d & 0.807 & a & 0.544 & b & 0.654 & b & 0.579 & b & 0.589 & $\mathrm{~b}$ & 0.620 & $\mathrm{~b}$ & 0.030 & $<.001$ \\
\hline ADG 7-16d & 47.7 & a & 34.3 & b & 38.1 & b & 35.4 & b & 35.4 & b & 35.9 & b & 1.1 & $<.001$ \\
\hline ADFI $7-16 d$ & 58.1 & a & 49.6 & b & 52.9 & $\mathrm{~b}$ & 50.5 & $\mathrm{~b}$ & 50.0 & $\mathrm{~b}$ & 49.7 & $\mathrm{~b}$ & 0.9 & $<.001$ \\
\hline G: F 7-16d & 0.822 & a & 0.691 & b & 0.715 & b & 0.702 & b & 0.708 & $\mathrm{~b}$ & 0.721 & $\mathrm{~b}$ & 0.012 & $<.001$ \\
\hline $\begin{array}{l}\text { ADG 16- } \\
21 d\end{array}$ & 75.1 & a & 73.2 & a & 77.8 & a & 73.4 & a & 74.9 & a & 72.3 & a & 1.6 & 0.125 \\
\hline $\begin{array}{l}\text { ADFI 16- } \\
21 d\end{array}$ & 98.9 & a & 89.4 & $\mathrm{~b}$ & 98.0 & $a b$ & 91.7 & $a b$ & 92.8 & $a b$ & 92.0 & $a b$ & 2.3 & 0.021 \\
\hline G:F 16-21d & 0.759 & b & 0.820 & a & 0.797 & $a b$ & 0.808 & $a b$ & 0.809 & $a b$ & 0.786 & $a b$ & 0.013 & 0.015 \\
\hline $\begin{array}{l}\text { ADG 21- } \\
28 d\end{array}$ & 107.1 & a & 101.3 & $\mathrm{~b}$ & 103.1 & $a b$ & 103.1 & $a b$ & 103.3 & $a b$ & 101.9 & $a b$ & 1.4 & 0.039 \\
\hline $\begin{array}{l}\text { ADFI 21- } \\
28 d\end{array}$ & 148.3 & a & 139.0 & b & 143.2 & $a b$ & 140.7 & $a b$ & 142.3 & $a b$ & 140.2 & b & 2.0 & 0.015 \\
\hline G:F 21-28d & 0.722 & a & 0.728 & a & 0.721 & a & 0.733 & a & 0.726 & a & 0.727 & a & 0.005 & 0.501 \\
\hline $\begin{array}{l}\text { ADG 28- } \\
35 d\end{array}$ & 115.9 & a & 118.2 & a & 114.9 & a & 119.2 & a & 115.4 & a & 116.9 & a & 2.2 & 0.677 \\
\hline $\begin{array}{l}\text { ADFI 28- } \\
35 d\end{array}$ & 177.4 & a & 176.2 & a & 175.3 & a & 176.1 & a & 176.0 & a & 175.5 & a & 1.8 & 0.971 \\
\hline G:F 28-35d & 0.654 & a & 0.671 & a & 0.655 & a & 0.677 & a & 0.655 & a & 0.666 & a & 0.010 & 0.290 \\
\hline $\begin{array}{l}\text { ADG 16- } \\
35 d\end{array}$ & 101.8 & a & 99.8 & a & 100.5 & a & 101.2 & a & 100.2 & a & 99.4 & a & 1.1 & 0.646 \\
\hline $\begin{array}{l}\text { ADFI 16- } \\
35 d\end{array}$ & 145.7 & a & 139.1 & a & 142.4 & a & 140.8 & a & 141.5 & a & 140.0 & a & 1.7 & 0.076 \\
\hline G:F $16-35 d$ & 0.699 & $\mathrm{~b}$ & 0.718 & $a b$ & 0.706 & $a b$ & 0.719 & a & 0.708 & $a b$ & 0.710 & $a b$ & 0.005 & 0.044 \\
\hline ADG $0-35 d$ & 64.4 & a & 58.5 & $\mathrm{~b}$ & 60.4 & b & 59.2 & b & 59.4 & $\mathrm{~b}$ & 58.6 & b & 0.9 & $<.001$ \\
\hline ADFI $0-35 d$ & 86.1 & a & 79.0 & b & 81.4 & b & 80.0 & $\mathrm{~b}$ & 80.8 & $\mathrm{~b}$ & 79.3 & b & 1.1 & $<.001$ \\
\hline G:F 0-35d & 0.748 & a & 0.740 & a & 0.742 & a & 0.740 & a & 0.735 & a & 0.740 & a & 0.004 & 0.143 \\
\hline
\end{tabular}

\footnotetext{
${ }^{1}$ Necrotic enteritis; ${ }^{2}$ Average daily gain; ${ }^{3}$ Average daily feed intake; ${ }^{4}$ Gain to feed ratio;

a-c LSmeans within a row lacking a common superscript differ $(P \leq 0.05)$.
} 
From 16 to $35 \mathrm{~d}$ of age, $\mathrm{ADG}$ and ADFI were not affected by (dietary) treatment ( $P=0.646$ and 0.076 , respectively; Table 4). Non-challenged and challenged treatments had similar ADG, ADFI, and G: $F$ from $28 \mathrm{~d}$ of age onwards ( $P>0.05$; Table 4). For the overall grower phase ( 16 to $35 \mathrm{~d}$ of age), broiler chickens fed $25 \%$ rye inclusion had the highest $\mathrm{G}: \mathrm{F}$ ratio whereas the non-challenged control treatment had the lowest $G$ : $F$ ratio ( $P=0.044$; Table 4).

\section{Performance 0 to $35 \mathrm{~d}$ of age: Overall study period}

Overall, the non-challenged control treatment had the highest ADG $(64.4 \mathrm{~g} / \mathrm{d})$ and ADFI $(86.1 \mathrm{~g} / \mathrm{d})$ compared to all challenged treatments (av. ADG $59.2 \mathrm{~g} / \mathrm{d}$ and ADFI $80.1 \mathrm{~g} / \mathrm{d}$; $\mathrm{P}<0.001$; Table 4). On the contrary, G:F ratio was not different between challenged and non-challenged treatments $(P=0.143$; Table 4). Overall performance ( $A D G, A D F I$ and $G: F$ ratio) did not differ significantly amongst any of the challenged treatments.

\section{Mortality and culling}

Results are reported as the probability for a higher mortality, so not as absolute mortality percentages per treatment. Culling is excluding broilers that were selected for dissection. Mortality and culling rates were not affected by (dietary) treatment (Table 5).

Table 5 Effect of (dietary) treatment, and effect of necrotic enteritis (NE) challenge, on mortality and culling from 0 to $35 \mathrm{~d}$ of age. Percentages reported are the probabilities for a higher mortality

\begin{tabular}{|c|c|c|c|c|c|c|c|c|}
\hline $\begin{array}{l}\text { NE challenge } \\
\text { Dietary treatment } \\
(0-7 \mathrm{~d})\end{array}$ & No & $\begin{array}{l}\text { Yes } \\
\text { Control }\end{array}$ & $\begin{array}{c}\text { Yes } \\
\text { Antibiotic } \\
\text { Octacillin }\end{array}$ & $\begin{array}{l}\text { Yes } \\
\text { Rye } \\
25 \%\end{array}$ & $\begin{array}{c}\text { Yes } \\
\beta \text {-glucan } \\
0.2 \%\end{array}$ & $\begin{array}{c}\text { Yes } \\
\text { Butyrate } \\
0.1 \%\end{array}$ & SEM & $\begin{array}{c}\text { P. } \\
\text { value }\end{array}$ \\
\hline Mortality, \% & 4.3 & 6.0 & 5.4 & 4.9 & 5.4 & 3.3 & 1.8 & 0.876 \\
\hline Mortality and culling, \% & 4.6 & 9.3 & 10.5 & 7.0 & 6.4 & 8.1 & 2.3 & 0.369 \\
\hline
\end{tabular}

\subsection{Effect of nutritional interventions on jejunal microbiota}

\section{Microbiota diversity}

The microbiota diversity, Shannon index, was measured for all treatment groups with respect to jejunum. For the colon, only the control and butyrate groups were examined (Table 6).

Table 6. Shannon diversity at $7 \mathrm{~d}$ of age for jejunum (all treatment groups) and colon (control and butyrate)

$\begin{array}{lccc}7 \text { d of age } & \text { Group }^{1} & \text { Mean } & \text { SEM } \\ & \text { CON } & 0.46 & 0.07 \\ & \text { CON_NE } & 0.53 & 0.05 \\ \text { Jejunum }^{2} & \text { ANT } & 0.60 & 0.14 \\ & \text { RYE } & 0.48 & 0.12 \\ & \text { BG } & 0.65 & 0.08 \\ & \text { BUTY } & 0.4 & 0.08 \\ \text { Colon }^{3} & \text { CON } & 1.50 & 0.08 \\ & \text { CON_NE } & 1.48 & 0.08 \\ & \text { BUTY } & 1.37 & 0.08\end{array}$

${ }^{1} \mathrm{CON}$, unchallenged control $(n=12)$; CON_NE, challenged control $(n=12)$; ANT, antibiotics $(n=12)$; RYE, rye $(25 \%)(n=12)$; BG, beta-glucans $(n=12)$; BUTY, coated butyrate $(n=12),{ }^{2}$ ANOVA; $p$-value $=$ $0.65,{ }^{3}$ ANOVA; $p$-value $=0.74$,

${ }^{4}$ Note that these birds were not challenged yet. 


\section{Redundancy analysis}

For both jejunum and colon, a redundancy analysis was performed for intestinal samples of broiler chickens at $7 \mathrm{~d}$ of age, in order to identify whether the intervention groups differed in overall microbiota composition. Intestinal microbiota composition of the broiler chickens that received an antibiotic in the drinking water deviated from the (un)challenged control groups, as a low overlap was observed (Figure 2). Other treatment groups shared the overall microbiota composition, but there were about 1 to 5 broiler chickens per treatment that showed more variation compared to the control treatment. In the colon no clear differences were observed between the butyrate group and the (un) challenged control groups (Figure 3).

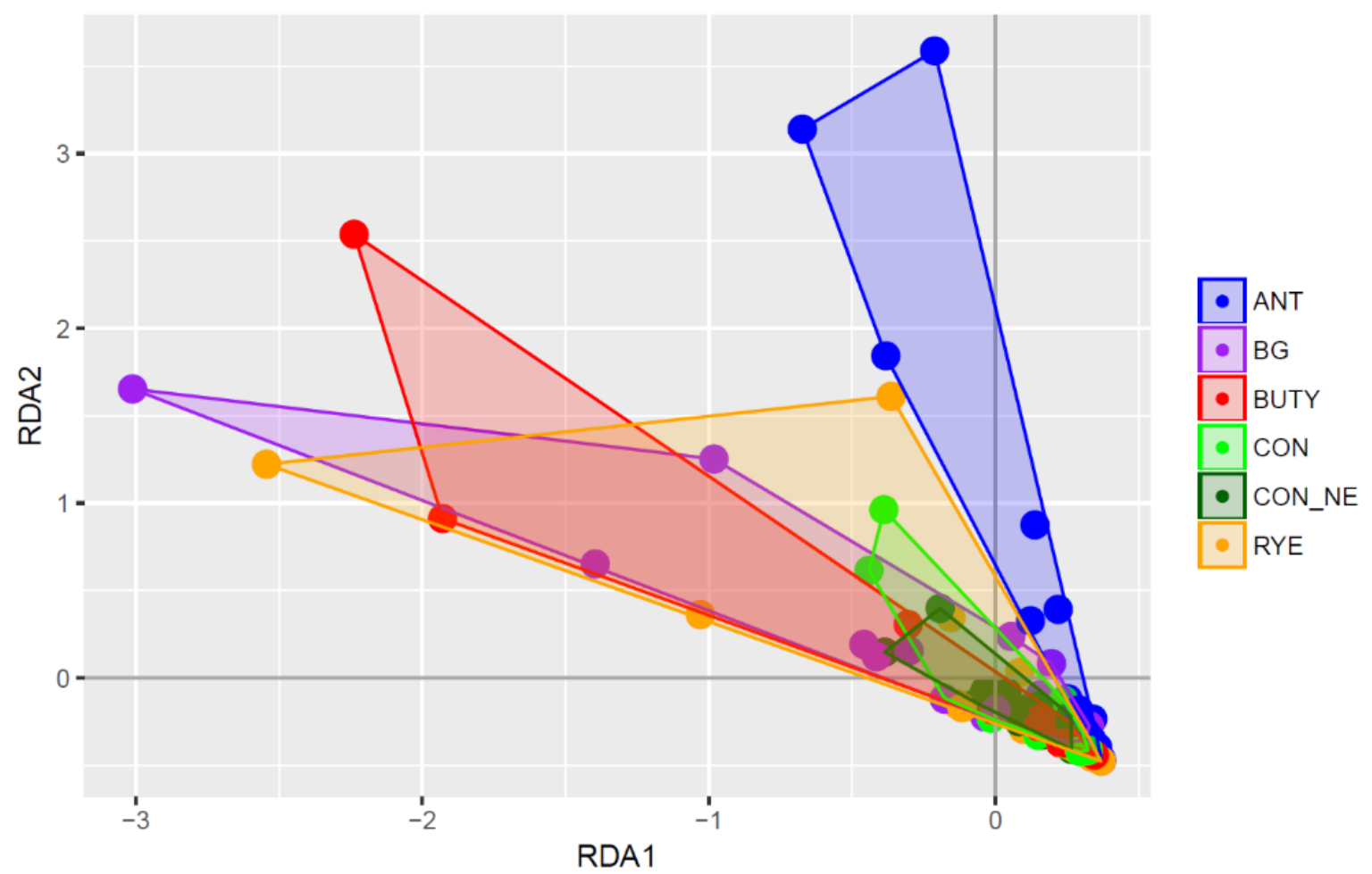

Figure 2. Redundancy analysis of jejunum microbiota ( $7 \mathrm{~d}$ of age)

The $x$-axis depicts RDA1 and the $y$-axis depicts RDA2. Each dot represents an individual broiler chicken, and each colour a (dietary) treatment: antibiotic in drinking water (ANT; Blue, $n=20$ ), $\beta$-glucans (BG; Purple, $n=18$ ), butyrate (BUTY; Red, $n=17$ ), unchallenged control (CON; Green; $n=19)$, challenged control (CON_NE, Darkgreen, $n=18)$ and rye (RYE; Orange, $n=18$ ). Note that the CON_NE birds were not challenged yet. 


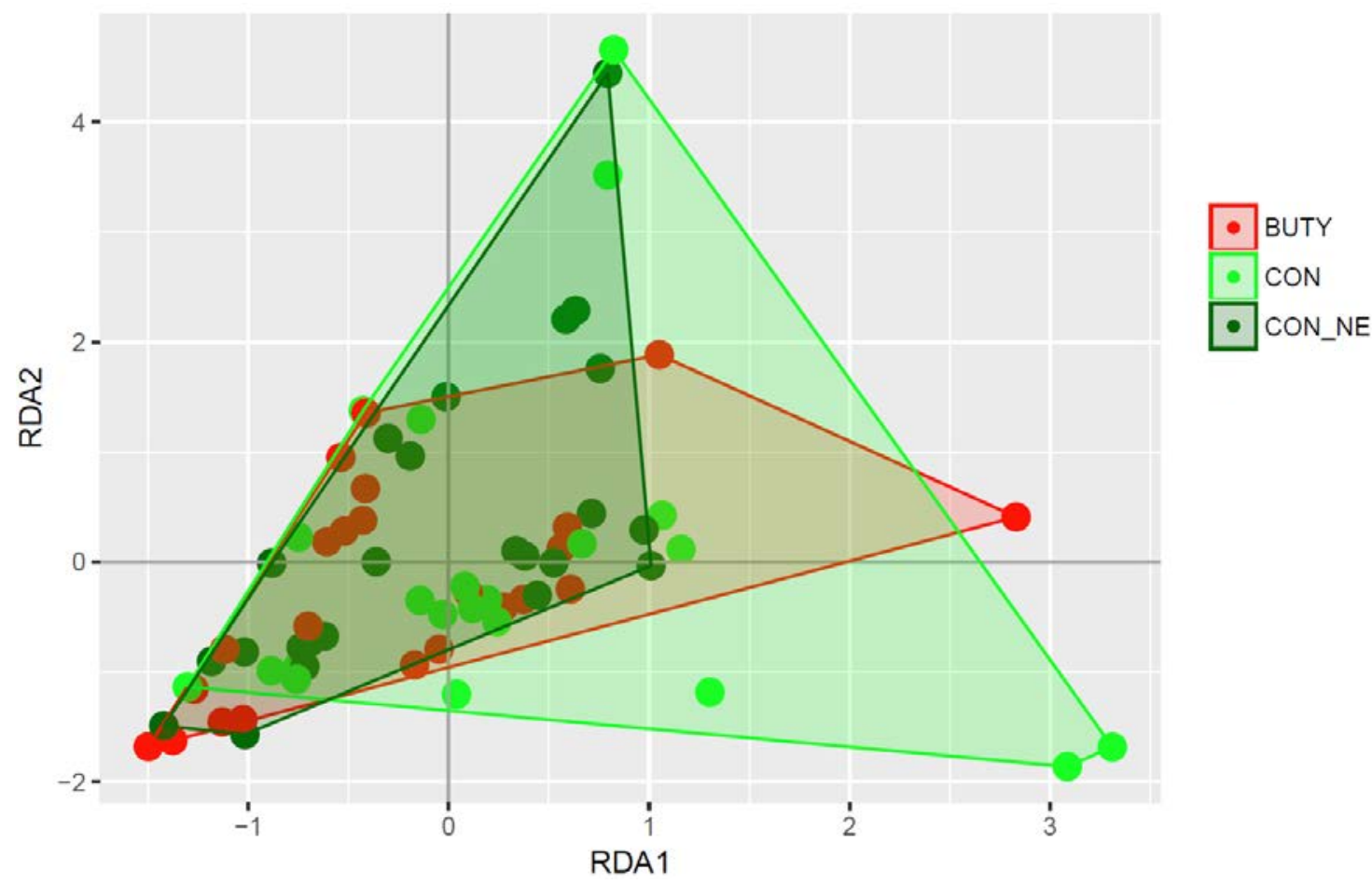

Figure 3. Redundancy analysis of colon microbiota ( $7 \mathrm{~d}$ of age).

The $\mathrm{x}$-axis depicts RDA1 and the $\mathrm{y}$-axis depicts PC1. Each dot represents an individual broiler chicken, and each colour a (dietary) treatment: unchallenged control ( $C O N$; Green, $n=23$ ), challenged control (CON_NE; Darkgreen, $n=24$ ) and butyrate (BUTY; Red, $n=23$ ). Note that the CON_NE birds were not challenged yet.

\section{Microbiota composition on genus level}

A test was performed at genus level in order to identify differences between the intervention groups and the (un)challenged controls. In the jejunum, the antibiotic treatment (ANT) showed 10 different bacterial genera and relatively large changes in Average Relative Contribution (ARC) were observed compared to the respective (un)challenged control (Table 7). For example, Enterococcus represented a $4.4 \%$ ARC in the unchallenged control group and $5.4 \%$ in the challenged control group versus $0.3 \%$ in the antibiotic group, whereas Enterobacteriaceae were higher in the antibiotic group (6.6\% ARC) compared to the un- and challenged control groups ( 1.0 and $0.4 \%$ ARC respectively).

For the rye treatment, up to 13 different genera were significant different when comparing to the control group (Table 7). However, the ARC was generally low in both groups (all below 1\%). Only two significant difference was observed, i.e. Lactobacillus and Enterococcaceae. The ARC of Lactobacillus was lower in the beta-glucan group (78.4\%) compared to the (un)challenged control group, the ARC were $88.7 \%$ and $89.2 \%$ respectively. For the butyrate group, both jejunum and colon were investigated. In jejunum, four bacterial genera were significant and in colon as well four bacterial genera were significant, however not the same bacterial genera were significant in the two tissues. Moreover, in jejunum the ARC of all significant bacterial genera were low (under $1 \%$ ). However, in colon the Enterobacteriaceae were decreased in the butyrate group $(3.9 \%$ ARC vs. $4.7 \%$ ARC in the averaged control group). 
Table 7. Overview of statistical significant genera between (dietary) treatment groups versus (un) challenged controls in jejunum and colon of broiler chickens at $7 \mathrm{~d}$ of age

\begin{tabular}{|c|c|c|c|c|c|c|c|c|c|c|c|}
\hline \multirow{2}{*}{$\mathrm{TRT}^{1}$} & \multirow{2}{*}{ Phylum } & \multirow{2}{*}{ Class } & \multirow{2}{*}{ Family } & \multirow{2}{*}{ Genus } & \multirow{2}{*}{$\mathrm{CON}^{2}$} & \multirow{2}{*}{ CON_NE ${ }^{2}$} & \multirow{2}{*}{$\mathrm{TRT}^{2}$} & \multicolumn{2}{|c|}{ TRT vs. CON } & \multicolumn{2}{|c|}{ TRT vs. CON_NE } \\
\hline & & & & & & & & P-value & $F D R^{3}$ & P-value & FDR \\
\hline \multirow{10}{*}{$\begin{array}{l}\text { ANT } \\
\text { jejunum }\end{array}$} & Actinobacteria & Actinobacteria & Dermabacteraceae & Brachybacterium & $<0.01$ & $<0.01$ & 0.039 & $<0.01$ & $<0.01$ & $<0.01$ & 0.01 \\
\hline & Firmicutes & Bacilli & & & 0.111 & 0.151 & 0.031 & $<0.01$ & $<0.01$ & $<0.01$ & $<0.01$ \\
\hline & Firmicutes & Bacilli & Enterococcaceae & Enterococcus & 4.438 & 5.365 & 0.283 & $<0.01$ & $<0.01$ & $<0.01$ & $<0.01$ \\
\hline & Firmicutes & Bacilli & Pediococcus & & $<0.01$ & $<0.01$ & 0.857 & $<0.01$ & $<0.01$ & $<0.01$ & 0.04 \\
\hline & Firmicutes & Bacilli & Leuconostocaceae & & 0.164 & 0.089 & 0.029 & $<0.01$ & 0.15 & $<0.01$ & 0.05 \\
\hline & Firmicutes & Bacilli & Other & Other & 0.182 & 0.225 & 0.070 & $<0.01$ & $<0.01$ & $<0.01$ & $<0.01$ \\
\hline & Firmicutes & Clostridia & Clostridiaceae & & $<0.01$ & 0.011 & $<0.01$ & $>0.05$ & $>0.05$ & 0.02 & 0.38 \\
\hline & Firmicutes & Clostridia & Clostridiaceae & Candidatus.Arthromitus & 0.629 & 0.521 & $<0.01$ & 0.02 & 0.39 & $<0.01$ & 0.02 \\
\hline & Firmicutes & Clostridia & Peptostreptococcaceae & & 0.048 & 0.040 & $<0.01$ & $>0.05$ & $>0.05$ & 0.01 & 0.37 \\
\hline & Proteobacteria & Gammaproteobacteria & Enterobacteriaceae & & 1.046 & 0.356 & 6.643 & 0.02 & 0.39 & $<0.01$ & 0.05 \\
\hline \multirow{13}{*}{$\begin{array}{l}\text { RYE } \\
\text { jejunum }\end{array}$} & Actinobacteria & Actinobacteria & Corynebacteriaceae & Corynebacterium & 0.043 & 0.064 & $<0.01$ & 0.01 & 0.59 & $>0.05$ & $>0.05$ \\
\hline & Cyanobacteria & Choloroplast & & & 0.241 & 0.212 & 0.105 & 0.01 & 0.59 & 0.02 & 0.56 \\
\hline & Firmicutes & Bacilli & & & 0.111 & 0.151 & 0.050 & $>0.05$ & $>0.05$ & 0.00 & 0.42 \\
\hline & Firmicutes & Bacilli & Leuconostocaceae & & 0.164 & 0.089 & 0.010 & 0.02 & 0.59 & 0.01 & 0.44 \\
\hline & Firmicutes & Bacilli & Other & Other & 0.182 & 0.225 & 0.095 & $>0.05$ & $>0.05$ & 0.01 & 0.44 \\
\hline & Firmicutes & Clostridia & & & 0.297 & 0.496 & 0.790 & $>0.05$ & $>0.05$ & 0.04 & 0.58 \\
\hline & Firmicutes & Clostridia & Clostridiaceae & Clostridium & 0.014 & 0.053 & 0.012 & 0.03 & 0.59 & 0.02 & 0.54 \\
\hline & Firmicutes & Clostridia & Lachnospiraceae & Blautia & 0.081 & 0.139 & 0.104 & $>0.05$ & $>0.05$ & 0.02 & 0.54 \\
\hline & Firmicutes & Clostridia & Lachnospiraceae & Coprococcus & 0.044 & 0.055 & 0.056 & $>0.05$ & $>0.05$ & 0.05 & 0.58 \\
\hline & Firmicutes & Clostridia & Lachnospiraceae & Dorea & 0.026 & 0.035 & 0.040 & $>0.05$ & $>0.05$ & 0.04 & 0.58 \\
\hline & Firmicutes & Clostridia & Ruminococcaceae & Ruminococcus & 0.066 & 0.095 & 0.211 & $>0.05$ & $>0.05$ & 0.05 & 0.58 \\
\hline & Proteobacteria & Alphaproteobacteria & mitochondria & Other & 0.022 & 0.013 & $<0.01$ & $>0.05$ & $>0.05$ & 0.01 & 0.44 \\
\hline & Other & Other & Other & Other & 0.305 & 0.709 & 0.160 & $>0.05$ & $>0.05$ & 0.02 & 0.49 \\
\hline \multirow{3}{*}{$\begin{array}{l}\text { BG } \\
\text { jejunum }\end{array}$} & Firmicutes & Bacilli & Enterococcaceae & Other & $<0.01$ & $<0.01$ & 0.013 & 0.03 & 0.64 & $>0.05$ & $>0.05$ \\
\hline & Firmicutes & Bacilli & Lactobacillaceae & Lactobacillus & 88.670 & 89.196 & 78.430 & 0.02 & 0.64 & $>0.05$ & $>0.05$ \\
\hline & Other & Other & Other & Other & 0.12 & 0.08 & 0.21 & $>0.05$ & $>0.05$ & 0.01 & 0.62 \\
\hline \multirow{3}{*}{$\begin{array}{l}\text { BUTY } \\
\text { jejunum }\end{array}$} & Firmicutes & Clostridia & Clostridiaceae & Candidatus.Arthromitus & 0.63 & 0.52 & $<0.01$ & $>0.05$ & $>0.05$ & $<0.01$ & 0.38 \\
\hline & Firmicutes & Clostridia & Lachnospiraceae & Blautia & 0.08 & 0.14 & 0.04 & $>0.05$ & $>0.05$ & 0.03 & 0.62 \\
\hline & Firmicutes & Clostridia & Lachnospiraceae & Dorea & 0.03 & 0.03 & 0.01 & $>0.05$ & $>0.05$ & 0.04 & 0.62 \\
\hline \multirow{4}{*}{$\begin{array}{l}\text { BUTY } \\
\text { colon }\end{array}$} & Firmicutes & Bacilli & Enterococcaceae & Other & 0.013 & 0.039 & 0.035 & 0.03 & 0.63 & $>0.05$ & $>0.05$ \\
\hline & Firmicutes & Clostridia & Clostridiaceae & SMB53 & $<0.01$ & $<0.01$ & 0.015 & 0.02 & 0.63 & $>0.05$ & $>0.05$ \\
\hline & Firmicutes & Clostridia & Veillonellaceae & Veillonella & 0.027 & $<0.01$ & $<0.01$ & 0.04 & 0.63 & $>0.05$ & $>0.05$ \\
\hline & Proteobacteria & Gammaproteobacteria & Enterobacteriaceae & & 6.551 & 2.964 & 3.894 & 0.05 & 0.63 & $>0.05$ & $>0.05$ \\
\hline
\end{tabular}

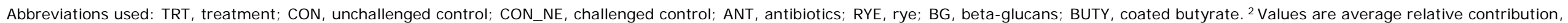

${ }^{3}$ False discovery rate 
For semi-quantification of the microbiota, both the $16 \mathrm{~S}$ and Green Fluorescent Protein (GFP) cycli were quantified by qPCR (Table 8). The first column shows the intervention groups. The second column depicts the Ct value (threshold cycle; is the PCR read-out) of the reference gene, here green fluorescent protein (GFP), for each intervention group. This gene is used to correct for the PCRfeasibility of the samples. This gene expression of the reference gene is a measure of the efficiency of the PCR. The third column contains the amount of GFP which is calculated based on the Ct value and the calibration line (data not shown). The fourth column contains the Ct value of our target genes (16S). The same gene (primer-pair) that was used in the microbiota sequence analysis. This gene is a measure of the amount of microbiota present in the intervention group. The fifth column contains the ratio of $16 \mathrm{~S}$ Ct divided by GFP Ct.

The lowest quantity for the ratio of $16 \mathrm{~S}$ and GFP was observed for control (CON) 0.06, whereas the highest was the rye (RYE) group (0.54). Both antibiotics (ANT) and beta-glucans (BG) where two times higher than the control group. The butyrate (BUTY) group was slightly higher than the controls. As shown in earlier work the use of antibiotics does not automatically result in a lower quantity, compared to the control the antibiotic group is even higher, although antibiotics suppress growth of certain bacterial groups it also enables all other bacterial species to flourish.

Table 8. Results of semi-quantification of microbiota for different (dietary) treatment groups in jejunum of 7 days old-broilers

$\begin{array}{lccccc}\text { Group } & \text { 16S Ct } & \text { Quantity } & \text { GFP Ct } & \text { Quantity } & \text { ratio 16S/ GFP Quantity } \\ \text { CON } & 19.7 & 75.8 & 26.4 & 1650.7 & \mathbf{0 . 0 6} \\ \text { CON_NE }^{1} & 19.1 & 119.8 & 25.8 & 1687.0 & \mathbf{0 . 0 7} \\ \text { ANT } & 18.7 & 208.4 & 25.9 & 1888.2 & \mathbf{0 . 1 2} \\ \text { RYE } & 19.9 & 78.2 & 26.8 & 1538.6 & \mathbf{0 . 5 4} \\ \text { BG } & 19.7 & 97.6 & 26.9 & 1189.4 & \mathbf{0 . 1 2} \\ \text { BUTY } & 18.6 & 155.9 & 25.8 & 2342.4 & \mathbf{0 . 0 7}\end{array}$

${ }^{1}$ Note that these birds were not challenged yet.

Abbreviations used: CON, unchallenged control; CON_NE, challenged control; ANT, antibiotics; RYE, rye (25\%); BG, beta-glucans; BUTY, coated butyrate

\subsection{Effect of feed interventions on transcriptomics in jejunum at day 7}

The effect of the inclusion of amoxicillin, rye, $\beta$-glucans, or butyrate into the diet on gene expression in jejunum was studied. Here, we focused on the significant genes, followed by pathway analysis. This analysis was performed by transcriptomic profiling analysis.

\subsubsection{Differential gene expression between feed interventions and control broilers}

There were differences in jejunal gene expression between the different feed interventions and control birds at day 7 (Table 9). Only the antibiotic treatment (ANT) differed from the (un)challenged control groups. Antibiotic versus the unchallenged control showed 417 differentially expressed probes, mapping to 240 annotated genes, whereas the antibiotic versus the challenged control showed 470 differentially expressed probes, mapping to 266 annotated genes.

Table 9. Differentially expressed genes ${ }^{1}$ in jejunum at day 7

\begin{tabular}{lcc}
\hline Contrast & Probes & Annotated Genes \\
\hline ANT vs. CON & 417 & 240 \\
ANT vs. CON_NE & 470 & 266 \\
RYE vs. CON & 0 & 0 \\
RYE vs. CON_NE & 0 & 0 \\
BG vs. CON & 0 & 0 \\
BG vs. CON_NE & 0 & 0 \\
BUTY vs. CON & 0 & 0 \\
BUTY vs. CON_NE & 0 & 0 \\
\hline
\end{tabular}

${ }^{1}$ Adjusted $p$-value (False Discovery Rate) $<0.05$ and FoldChange $>|1.5| .{ }^{2}$ Note that these birds were not challenged yet. Abbreviations used: CON, unchallenged control; CON_NE, challenged control; ANT, antibiotics; RYE, rye (25\%); BG, 


\subsubsection{Pathway analysis}

In order to investigate in which biological pathways these genes were involved, we performed a pathway analysis. An overview of the significant pathways is shown in Table 10, in total 28 pathways had an adjusted P-value below 0.05 .

Table 10. Significant pathways when comparing the antibiotic group vs. challenged and unchallenged controls

\begin{tabular}{|c|c|c|c|c|}
\hline \multicolumn{5}{|l|}{ Unchallenged control } \\
\hline Pathway Name & Score & $\begin{array}{l}\text { Total } \\
\text { Genes }\end{array}$ & $\begin{array}{c}\text { Matched } \\
\text { Genes }\end{array}$ & $\%$ \\
\hline NF-kappaB Signaling & 25.36 & 313 & 16 & 5.11 \\
\hline Akt Signaling & 22.48 & 681 & 22 & 3.23 \\
\hline TGF-Beta Pathway & 21.45 & 652 & 21 & 3.22 \\
\hline PAK Pathway & 20.41 & 682 & 21 & 3.08 \\
\hline Cytokine Signaling in Immune System & 19.82 & 761 & 22 & 2.89 \\
\hline ERK Signaling & 19.29 & 1177 & 28 & 2.38 \\
\hline PEDF Induced Signaling & 19.15 & 721 & 21 & 2.91 \\
\hline Interleukin- 4 and 13 Signaling & 16.76 & 114 & 8 & 7.02 \\
\hline Cytokine Production By Th17 Cells in CF (Mouse Model) & 16.65 & 54 & 6 & 11.11 \\
\hline Allograft Rejection & 16.02 & 249 & 11 & 4.42 \\
\hline Th17 Cell Differentiation & 15.96 & 162 & 9 & 5.56 \\
\hline $\begin{array}{l}\text { IL-4 Signaling Pathways and Their Primary Biological Effects in Different } \\
\text { Immune Cell Types }\end{array}$ & 15.79 & 17 & 4 & 23.53 \\
\hline Type II Interferon Signaling (IFNG) & 15.49 & 37 & 5 & 13.51 \\
\hline Innate Immune System & 14.60 & 2132 & 37 & 1.74 \\
\hline NRF2 Pathway & 14.31 & 145 & 8 & 5.52 \\
\hline NF-KappaB Family Pathway & 13.98 & 241 & 10 & 4.15 \\
\hline \multicolumn{5}{|l|}{ Challenged control* } \\
\hline Pathway Name & Score & $\begin{array}{l}\text { Total } \\
\text { Genes }\end{array}$ & $\begin{array}{l}\text { Matched } \\
\text { Genes }\end{array}$ & $\%$ \\
\hline Collagen Chain Trimerization & 18.13 & 184 & 11 & 5.98 \\
\hline NF-kappaB Signaling & 17.72 & 313 & 14 & 4.47 \\
\hline Allograft Rejection & 16.49 & 249 & 12 & 4.82 \\
\hline Akt Signaling & 15.41 & 681 & 20 & 2.94 \\
\hline Cytokine Signaling in Immune System & 14.80 & 761 & 21 & 2.76 \\
\hline Type II Interferon Signaling (IFNG) & 14.51 & 37 & 5 & 13.51 \\
\hline PEDF Induced Signaling & 14.27 & 721 & 20 & 2.77 \\
\hline ERK Signaling & 13.94 & 1177 & 27 & 2.29 \\
\hline Development_Thrombopoetin Signaling Via JAK-STAT Pathway & 13.31 & 23 & 4 & 17.39 \\
\hline
\end{tabular}

* Note that these birds were not challenged yet.

Highlighted grey pathways are overlap between the antibiotic group and the unchallenged and challenged controls.

Subsequently, the most significant pathways were reviewed and general biological processes were extracted. This was followed by superimposing the gene expression data (fold change ANT vs. CON) on particular pathways of interest, i.e. the NF-kappa B signalling pathway (Figure 4), PI3K-Akt signalling pathway (Figure 5), Cytokine-cytokine receptor interaction (Figure 6), and Intestinal immune network for IgA production (Figure 7).

A highly significant pathway was the NF-kappa B pathway, which is important in regulation of cellular responses and can be induced by e.g. reactive oxygen species (ROS), TNFa, IL-1ß, lipopolysaccharides (LPS). In this pathway the majority of genes are down-regulated in the antibiotics groups vs the (un)challenged controls, most of these are (in) directly involved in immune related processes. However, genes involved in cell survival are up-regulated. Another highly significant pathway was the PI 3K-AKT 
signalling pathway, where we mostly observed down-regulated genes, except for the mTOR signalling pathway part. mTOR signalling has a broad range of functions, including actin/cytoskeleton reorganization and cell survival. An interesting pathway related to immunity is the cytokine-cytokine receptor interaction pathway, where down-regulation of genes was observed for the following families chemokines, hematopoietins (mainly the IL2RG subset), interferon, IL-10, IL-1, and IL-17, and upregulation for the families hematopoietins (mainly the IL6ST subset), PDGF, and TGFB. Most of these families are involved in immune related processes, like chemokines, hematopoietins, interferon, IL-10, IL-1, and IL-17. Whereas the PDGF and TGFB families are involved in developmental and wound healing functions, by stimulation of extracellular matrix production, influencing cell migration, cell adhesion, differentiation, and other cellular activities.

Because of the lower expression in immune related parts of the above mentioned pathways, we also investigated the intestinal immune network for IgA production pathway, in which we also observed that the majority of genes is down-regulated. 
A

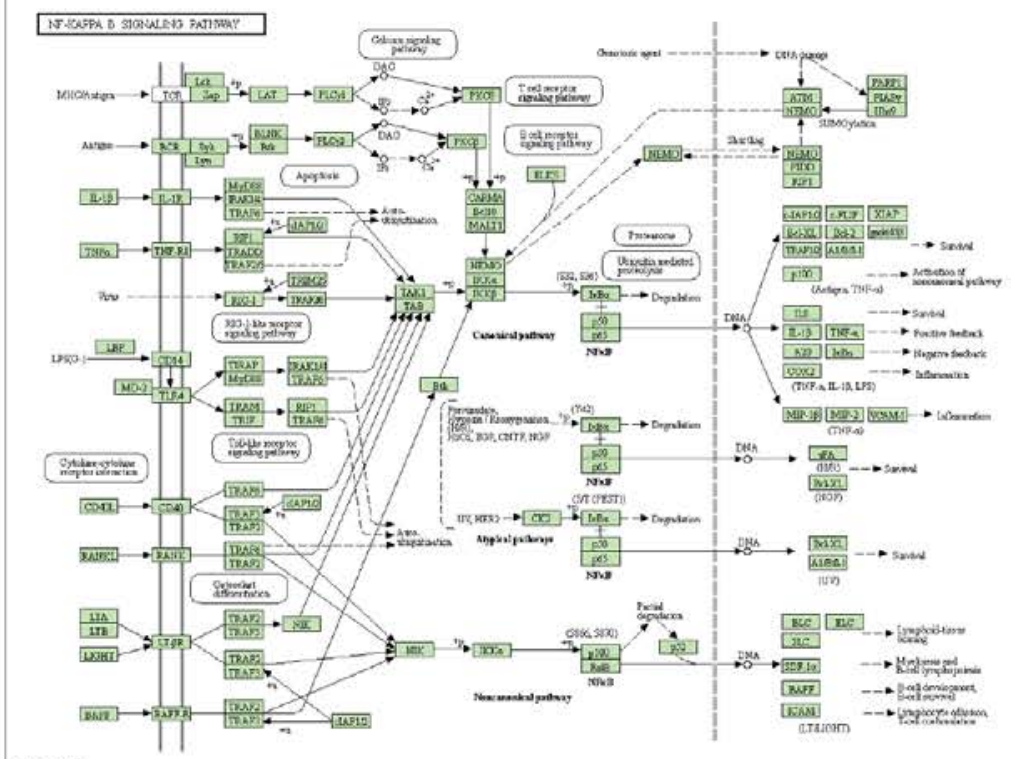

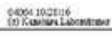

B

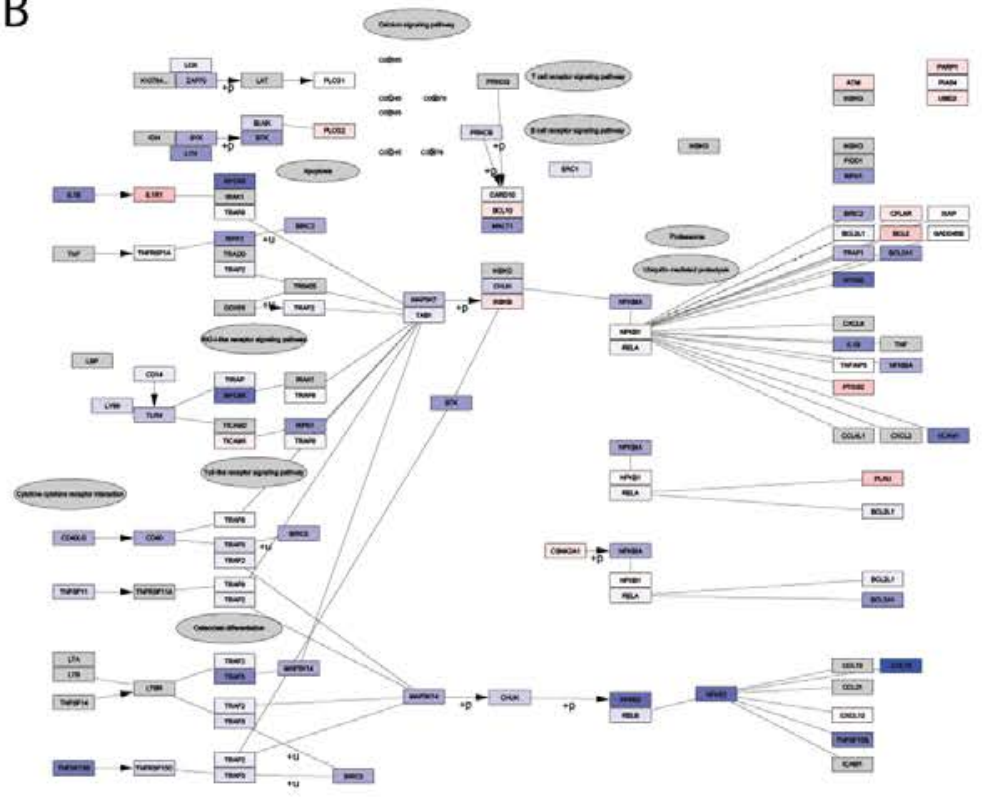

Figure 4. NF-kappa B signalling pathway

A) shows the NF-kappa B signalling pathway diagram as represented by Kyoto Encyclopedia of Genes and Genomes (KEGG). B and C show the same pathway as well, however the lay-out differs somewhat from the KEGG representation. In $\mathrm{B}$ genes are coloured by fold change (ANT vs. unchallenged control) and in $C$ genes are coloured by fold change (ANT vs challenged control). Where blue denotes down-regulated genes and red denotes up-regulated genes, grey denotes not measured by our transcriptomic analysis. See Appendix B for more detailed explanation and pdf version for better resolution.

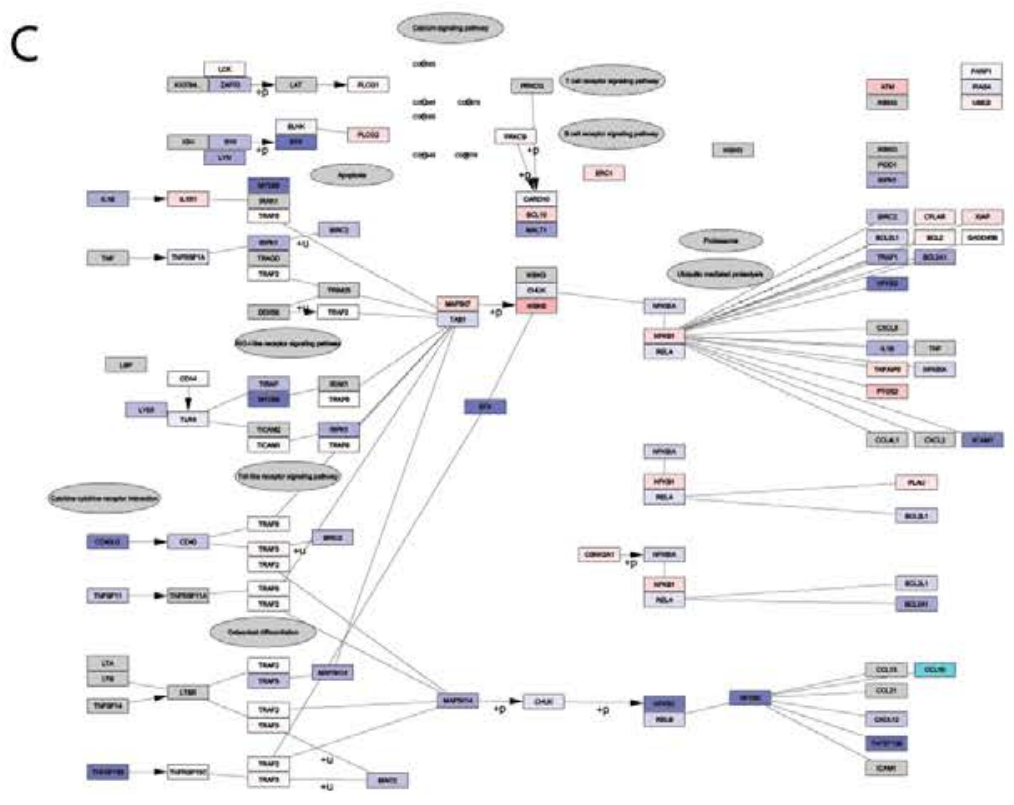


A

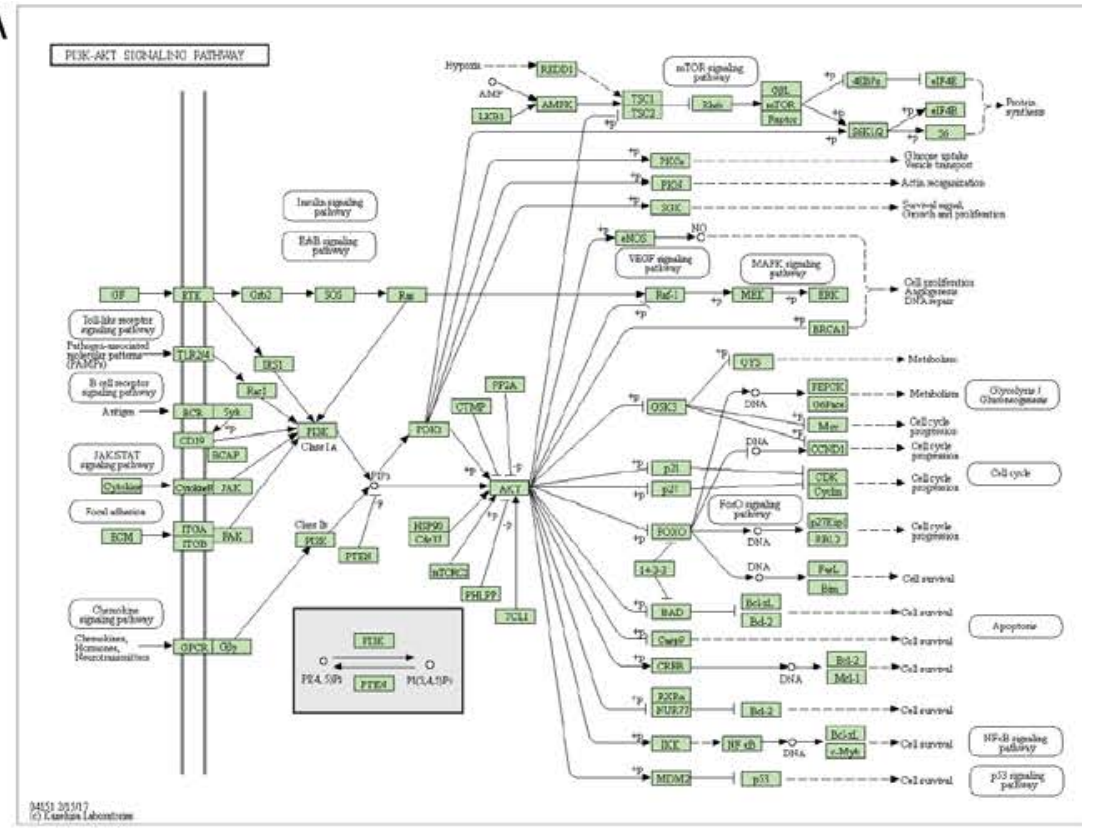

B

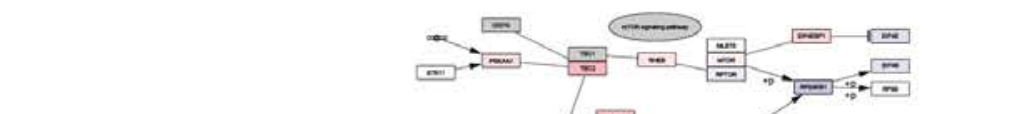

Figure 5. PI3K-Akt signalling pathway

A) shows the PI3K-Akt B signalling pathway diagram as represented by Kyoto Encyclopedia of Genes and Genomes (KEGG). B and C show the same pathway as well, however the lay-out differs somewhat from the KEGG representation. In B genes are coloured by fold change (ANT vs. unchallenged control) and in $C$ genes are coloured by fold change (ANT vs challenged control). Where blue denotes down-regulated genes and red denotes upregulated genes, grey denotes not measured by our transcriptomic analysis. See Appendix B for more detailed explanation and pdf version for better resolution.

C

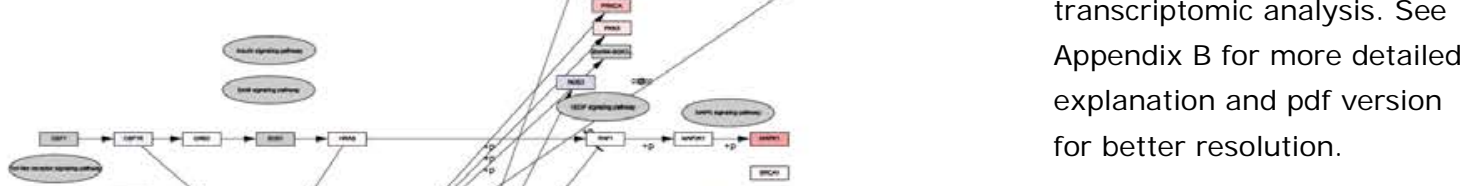
$-\infty$

$\infty$ $=-\infty$ $\frac{1}{2}=$ $1 \quad-\quad$ $=\infty$ $\frac{1}{1-\infty}=$

$\pm \infty$

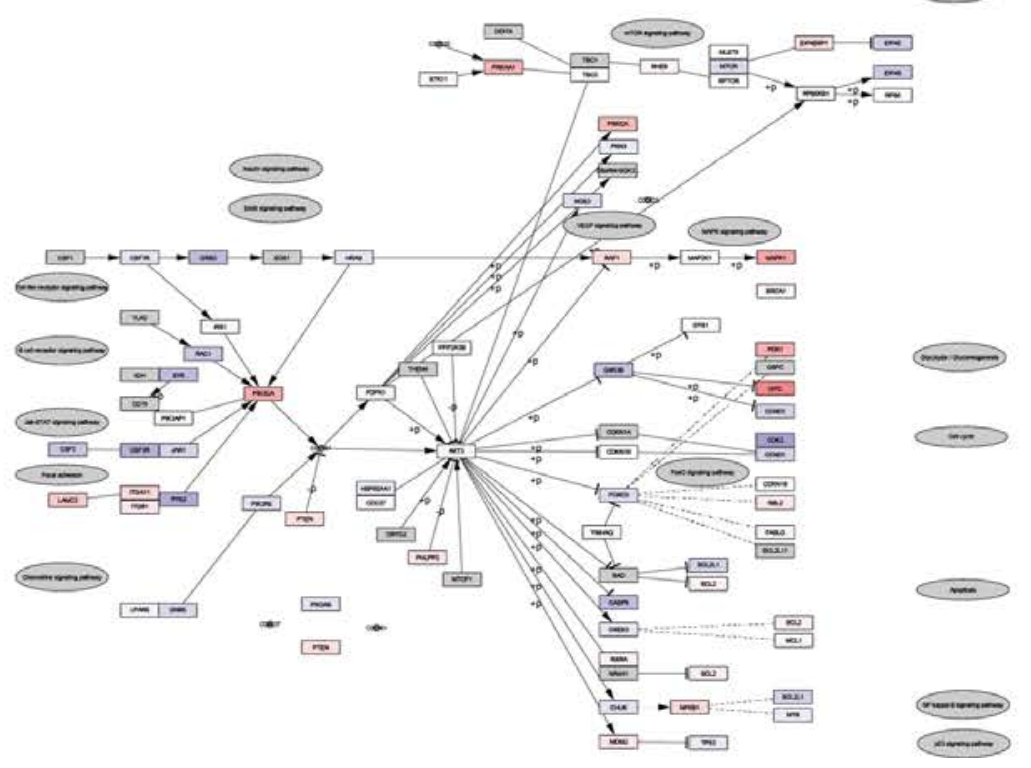




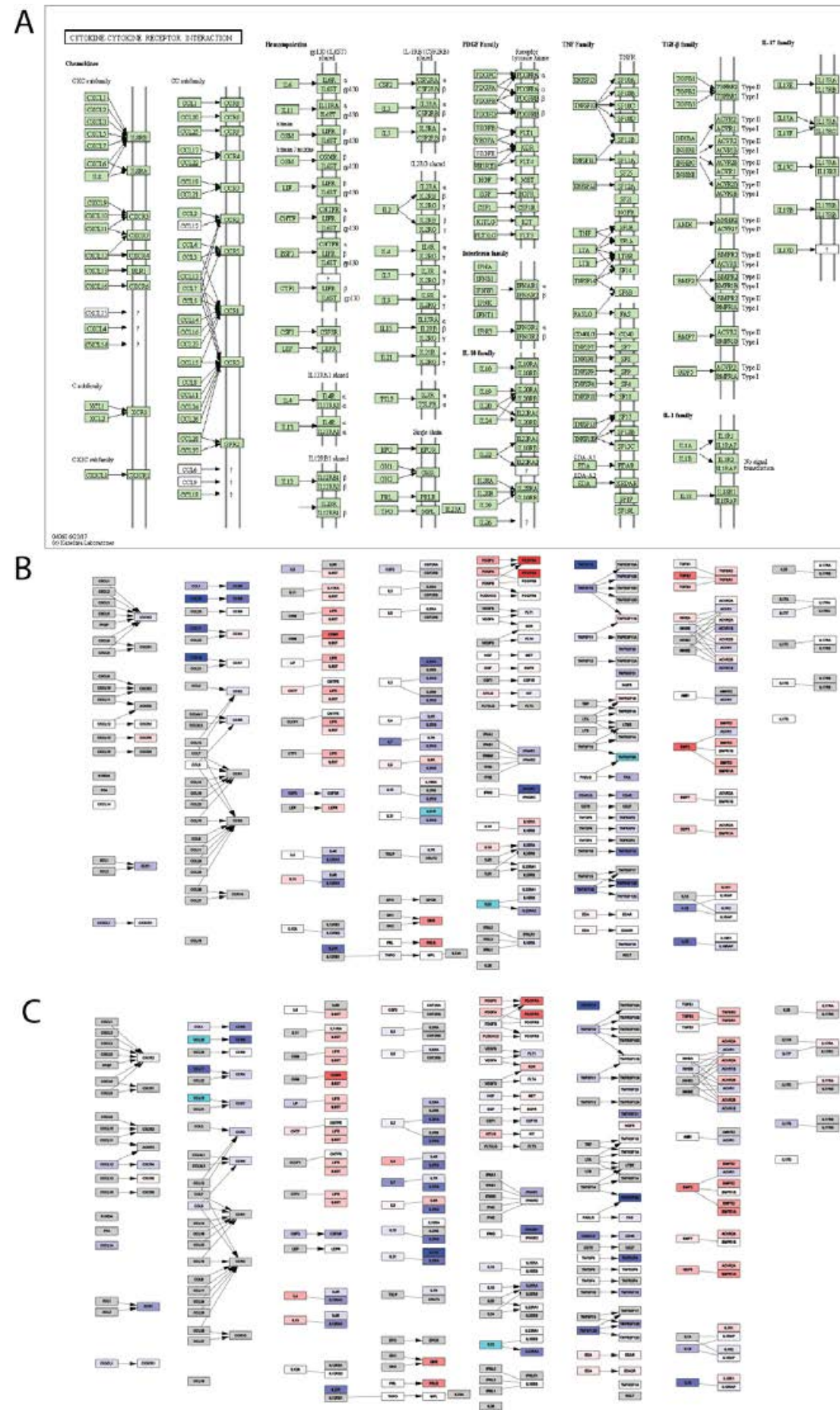

Figure 6. Cytokine-cytokine receptor interaction

A) shows the Cytokinecytokine receptor interaction diagram as represented by Kyoto Encyclopedia of Genes and Genomes (KEGG). B and $C$ show the same pathway as well, however the lay-out differs somewhat from the KEGG representation. In B genes are coloured by fold change (ANT vs. unchallenged control) and in $C$ genes are coloured by fold change (ANT vs challenged control). Where blue denotes down-regulated genes and red denotes upregulated genes, grey denotes not measured by our transcriptomic analysis. See Appendix B for more detailed explanation and pdf version for better resolution.

$-$ 


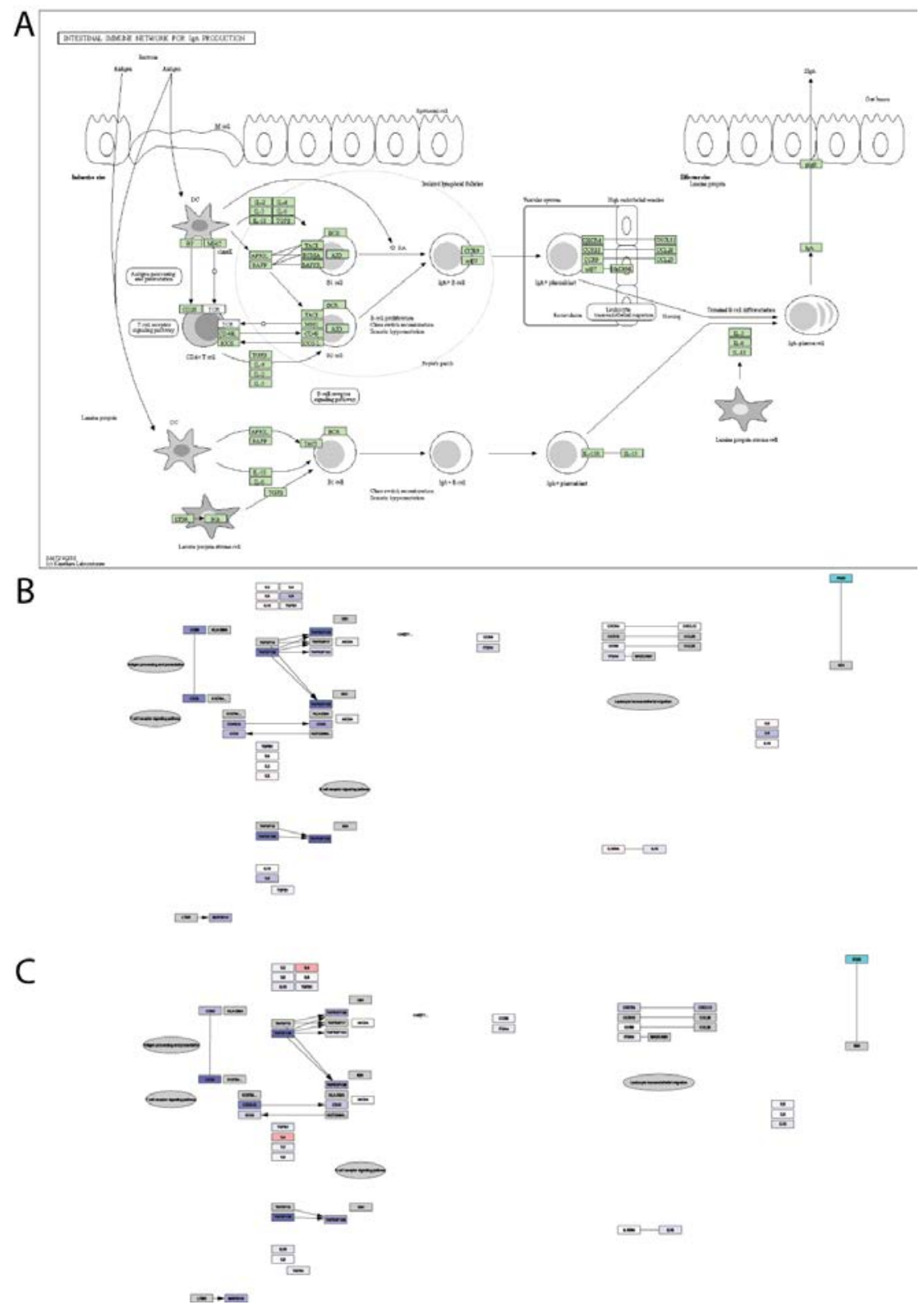

Figure 7. Intestinal immune network for IgA production

A) shows the intestinal immune network for IgA production pathway diagram as represented by Kyoto Encyclopedia of Genes and Genomes (KEGG). B and C show the same pathway as well, however the lay-out differs somewhat from the KEGG representation. In B genes are coloured by fold change (ANT vs. unchallenged control) and in $C$ genes are coloured by fold change (ANT vs challenged control). Where blue denotes down-regulated genes and red denotes upregulated genes, grey denotes not measured by our transcriptomic analysis. See Appendix $B$ for more detailed explanation and pdf version for better resolution. 


\subsection{Effect of feed interventions on jejunal histology}

J ejunal histology was measured on 7 and $14 \mathrm{~d}$ of age (Tables 11 and 12). At $7 \mathrm{~d}$ of age, broiler chickens that received the antibiotic treatment had a lower crypt depth and higher villi to crypt ratio (V:C) compared to the control treatment, whereas the number of goblet cells was not affected. A tendency was observed for lowered villi length comparing the antibiotic group versus the control group. Jejunal histology did not differ amongst any of the other (dietary) treatments.

Table 11. J Jejunum histology results for different (dietary) treatment groups of broiler chickens at $7 \mathrm{~d}$ of age

\begin{tabular}{|c|c|c|c|c|c|c|c|c|c|c|c|c|}
\hline & $\begin{array}{l}\text { CON } \\
\text { mean }\end{array}$ & $\begin{array}{l}\mathrm{CON} \\
\mathrm{sd}^{2}\end{array}$ & $\begin{array}{l}\text { CON_NE } \\
\text { mean }\end{array}$ & $\begin{array}{l}\text { CON_NE } \\
\text { sd }\end{array}$ & $\begin{array}{l}\text { ANT } \\
\text { mean }\end{array}$ & $\begin{array}{l}\text { ANT } \\
\text { sd }\end{array}$ & $\begin{array}{l}\text { RYE } \\
\text { mean }\end{array}$ & $\begin{array}{l}\text { RYE } \\
\text { sd }\end{array}$ & $\begin{array}{l}\text { BG } \\
\text { mean }\end{array}$ & $\begin{array}{l}\text { BG } \\
\text { sd }\end{array}$ & $\begin{array}{l}\text { BUTY } \\
\text { mean }\end{array}$ & $\begin{array}{l}\text { BUTY } \\
\text { sd }\end{array}$ \\
\hline $\begin{array}{l}\text { No. of goblet cells } \\
\text { per } \mathrm{mm} 2\end{array}$ & 1411 & $\begin{array}{l}371 . \\
4\end{array}$ & 1528 & 432.8 & 1435 & 348.3 & 1542 & 354 & 1383.8 & 390.9 & 1654.5 & 502.1 \\
\hline Crypt depth $(\mu \mathrm{m})$ & 111.2 & 21.7 & 121.4 & 28.9 & 85.6 & 11.8 & 126.7 & 36.9 & 107.4 & 29.3 & 104.7 & 18.7 \\
\hline Villi length $(\mu \mathrm{m})$ & ${ }_{a}^{501.2}$ & $\begin{array}{l}101 . \\
2\end{array}$ & $519.4^{\mathrm{a}}$ & 133.5 & $437.6^{\mathrm{b}}$ & 92.3 & $539.2^{a}$ & 112.4 & $465.6^{\mathrm{a}}$ & 124.6 & $509.6^{a}$ & 105.9 \\
\hline $\mathrm{V}: \mathrm{C}$ ratio & $4.6^{a}$ & 0.7 & $4.4^{(a)}$ & 1.1 & $5.1^{(b)}$ & 0.9 & $4.4^{a}$ & 1 & $4.4^{\mathrm{a}}$ & 0.8 & $4.9^{a}$ & 1 \\
\hline
\end{tabular}

${ }^{1}$ Note that these birds were not challenged yet. ${ }^{2} \mathrm{sd}=$ standard deviation. Abbreviations used: CON, unchallenged control $(n=12)$; CON_NE, challenged control $(n=12)$; ANT, antibiotics $(n=12)$; RYE, rye $(n=12)$; BG, beta-glucans ( $n=12)$; BUTY, coated butyrate $(n=12)$.

a, b Means in a row with different superscripts differ significantly $(P<0.05)$ from (un)challenged controls.

(a), (b) Means in a row with different superscripts between brackets indicate a trend $(0.05<\mathrm{P}<0.10)$ from (un) challenged controls.

At $14 \mathrm{~d}$ of age, broiler chickens from the control treatment with NE challenge had deeper crypts and a lower villi to crypt ratio compared to the negative control, whereas villi length and the number of goblet cells was not affected. Jejunal histology did not differ amongst any of the other (dietary) treatments.

Table 12. J Junum histology results for different (dietary) treatment groupsl of broiler chickens at $14 \mathrm{~d}$ of age

\begin{tabular}{|c|c|c|c|c|c|c|c|c|c|c|c|c|}
\hline & $\begin{array}{l}\text { CON } \\
\text { mean }\end{array}$ & $\begin{array}{l}\text { CON } \\
s^{1}\end{array}$ & $\begin{array}{l}\text { CON_NE } \\
\text { mean }\end{array}$ & $\begin{array}{l}\text { CON_NE } \\
\text { sd }\end{array}$ & $\begin{array}{l}\text { ANT } \\
\text { mean }\end{array}$ & $\begin{array}{l}\text { ANT } \\
\text { sd }\end{array}$ & $\begin{array}{l}\text { RYE } \\
\text { mean }\end{array}$ & $\begin{array}{l}\text { RYE } \\
\text { sd }\end{array}$ & $\begin{array}{l}\text { BG } \\
\text { mean }\end{array}$ & $\begin{array}{l}\text { BG } \\
\text { sd }\end{array}$ & $\begin{array}{l}\text { BUTY } \\
\text { mean }\end{array}$ & $\begin{array}{l}\text { BUTY } \\
\text { sd }\end{array}$ \\
\hline $\begin{array}{l}\text { No. of goblet } \\
\text { cells per } \mathrm{mm} 2\end{array}$ & 1563.1 & 317.2 & 1360.9 & 398.8 & 1402 & 365.3 & 1345.9 & 591.4 & 1256.5 & 396.1 & 1461.2 & 386.8 \\
\hline $\begin{array}{l}\text { Crypt depth } \\
(\mu \mathrm{m})\end{array}$ & $149.6^{\mathrm{b}}$ & 36.7 & $245.6 a^{a}$ & 50.3 & $203.9^{(\mathrm{c})}$ & 66.7 & $234.2^{a}$ & 58.3 & $239.5^{a}$ & 54.1 & $230.6^{a}$ & 51.4 \\
\hline $\begin{array}{l}\text { Villi length } \\
(\mu \mathrm{m})\end{array}$ & 610.7 & 90.2 & 524 & 88.4 & 558 & 103.2 & 543.8 & 113.6 & 566.8 & 170.4 & 586.5 & 127 \\
\hline V:C ratio & $4.3^{b}$ & 1 & $2.2^{\mathrm{a}}$ & 0.7 & $3^{a}$ & 1.1 & $2.5^{a}$ & 0.8 & $2.5^{a}$ & 0.9 & $2.7^{a}$ & 0.8 \\
\hline
\end{tabular}

${ }^{1} \mathrm{Sd}=$ standard deviation. ${ }^{2} \mathrm{CON}$, unchallenged control $(n=12) ;$ CON_NE, challenged control $(n=12) ;$ ANT, antibiotics $(n=12)$; RYE, rye $(n=12)$; BG, beta-glucans $(n=12)$; BUTY, coated butyrate $(n=12)$.

$a, b$ Means in a row with different superscripts differ significantly $(P<0.05)$.

(c) Means in a row with different superscripts between brackets indicate a trend $(0.05<\mathrm{P}<0.10)$. 


\subsection{Effect of feed interventions on lesion scores}

The probability for a higher lesion score for E. Maxima and C. perfringens at 14 and $15 \mathrm{~d}$ of age was not affected by (dietary) treatment (Table 13).

Table 13. Lesion scores ${ }^{1}$ for E. maxima and C. perfringens for different (dietary) treatment groups of broiler chickens at 14 and $15 \mathrm{~d}$ of age. Results are reported as the probability for a higher score

\begin{tabular}{lcccccccc} 
NE challenge & No & Yes & Yes & Yes & Yes & \multicolumn{1}{c}{ Yes } \\
Diet treatment (0-7d) & Control & Control & Antibiotic & Rye & $\beta$-glucans & Butyrate & SEM & P-value \\
E. maxima, d14 & 0.31 & 0.28 & 0.16 & 0.46 & 0.35 & 0.47 & 0.13 & 0.201 \\
C. perfringens, d14 & 0.32 & 0.3 & 0.22 & 0.36 & 0.22 & 0.4 & 0.11 & 0.601 \\
E. maxima, d15 & 0.89 & 0.8 & 0.71 & 0.87 & 0.68 & 0.79 & 0.25 & 0.483 \\
C. perfringens, d15 & 0.22 & 0.28 & 0.17 & 0.19 & 0.17 & 0.29 & 0.11 & 0.779 \\
\hline
\end{tabular}

${ }^{1}$ E. maxima lesions scored on scale 0-4: 1= One or some haemorrhages, $2=$ Several haemorrhages, $3=$ Many haemorrhages, orange mucus in the lumen, $4=$ Many haemorrhages, mucosal damage (free blood in the lumen). C. perfringens lesions scored on scale 0 - 4: $1=$ One to five lesion present in the intestine, $2=$ More than 5 single distinguished lesions, $3=$ Lesions merge or extend to a surface of more than $1 \mathrm{~cm}^{2}, 4=$ Pseudo membranes present in the intestine causing death.

In addition to the probability scores of having higher lesion scores, we also generated a frequency table and calculated the percentage of positive birds (birds having lesions (Table 14). For the Eimeria maxima related lesions, the challenged control shows $75 \%$ birds positive for lesions, where the antibiotic group is lowest $(63 \%)$ and the rye group highest $(95 \%)$. For the Clostridium perfringens related lesions the challenged control shows $42 \%$ birds positive for lesions, where the antibiotic group is lowest (38\%) and the butyrate group highest $(63 \%)$.

Table 14. Lesion scores ${ }^{1}$ for E. maxima and C. perfringens for different (dietary) treatment groups of broiler chickens at $14 \mathrm{~d}$ of age. Results are reported as frequency or percentage positive of total.

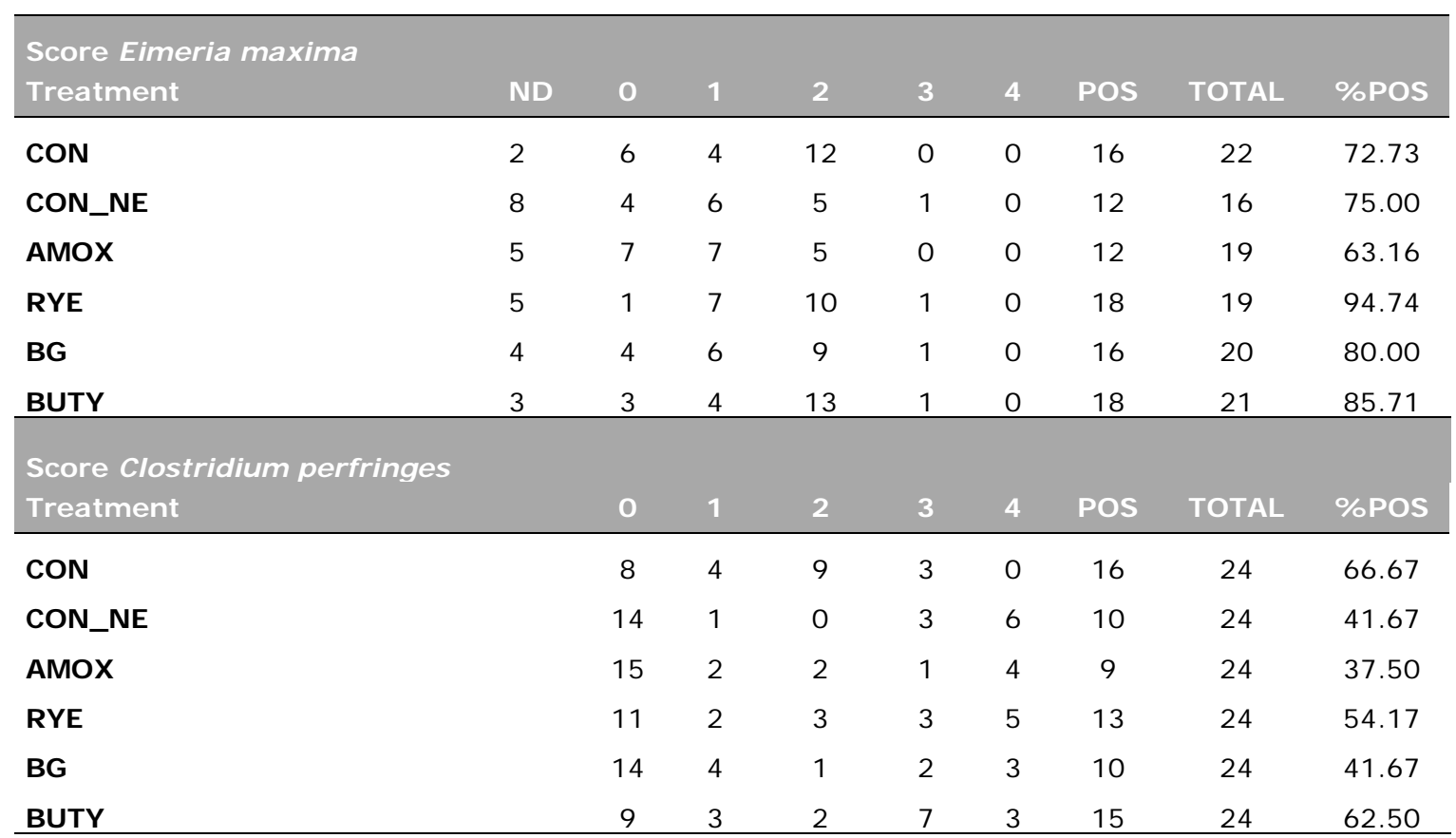

Abbreviations used: CON, unchallenged control; CON_NE, challenged control; ANT, antibiotics; RYE, rye; BG, betaglucans; BUTY, coated butyrate. 


\section{Discussion}

\subsection{NE Challenge}

Till date, necrotic enteritis is one of the most significant threats for the poultry industry. In clinical form it causes high mortality and in subclinical forms it affects growth and feed conversion. Necrotic enteritis is a multi-factorial disease process, in which a number of co-factors are usually required to precipitate an outbreak of the disease. Although $\mathrm{C}$. perfringens has been identified as the etiological agent of the disease, the predisposing factors that lead to over-proliferation of $C$. perfringens and the subsequent progression to disease are poorly understood [17].

For the current study, the NE challenge model included an infection with E. maxima to predispose the intestinal tract for a subsequent $C$. perfringens infection. The aim of the challenge was to induce a subclinical infection, affecting growth performance but not mortality. Growth performance was indeed affected due to the NE challenge, as challenged broiler chickens fed the control diet had a reduced average daily gain and feed intake, and a worsened gain to feed ratio compared to unchallenged chickens fed the same diet. As intended, mortality was not affected by the NE challenge. The effect of the NE challenge on growth performance was significant from 7 to $16 \mathrm{~d}$ of age, where after birds gradually recovered from the challenge. The impaired BW development as a result of the NE challenge could not be fully compensated for during the experimental period, resulting in a BW difference of $150 \mathrm{~g}$ between the challenged and unchallenged birds at $35 \mathrm{~d}$ of age. These findings are in line with other studies using the NE model [64, 65].

For all treatments, including the unchallenged control treatment, intestinal lesions were scored at 14 and $15 \mathrm{~d}$ of age. Also in the unchallenged broiler group, chickens had lesions, and probably got infected. Although it may be hypothesized that unchallenged broiler chickens may have gotten infected through the (supposed to be sterilized) inoculum they received, this appears to be unlikely. Hygiene measures applied during the execution of the study were intended to prevent any contact between challenged and unchallenged birds (using pen dividers to prevent excretion from one into another pen), as well as transmission of spores from one pen to the other during measurements (bird weighing, etc.) . Nevertheless, as challenged and unchallenged broiler chickens were housed in the same room, transmission may also have occurred through, e.g., dust particles in combination with ventilation.

\subsection{Antibiotics}

Broiler chickens that received antibiotics during their first week of life, had a higher body weight gain and feed intake compared to birds fed the control diet during this period, whereas gain to feed ratio was only numerically improved. Compared to the challenged control treatment, the numerically higher feed intake and body weight gain as a result of the antibiotic treatment remained until $16 \mathrm{~d}$ of age, where after both treatments performed similar unto the end of the experiment. The used antibiotic, amoxicillin, is a moderate-spectrum $\beta$-lactam antibiotic and has proven effects on susceptible Grampositive and Gram-negative bacteria [19]. Because of this, it was hypothesized that amoxicillin supplementation could improve growth performance of the chicken, which indeed was the case during the period of supplementation. Many studies showed improved growth performance in antibiotic supplemented broilers [66, 67]. In the study of Salim et al. [66], in which broiler chickens were supplemented with virginiamycin up to $35 \mathrm{~d}$ of age, however, feed intake and feed conversion ratio were only improved during the first week of life, whereas body weight gain was improved up to $21 \mathrm{~d}$ of age. Broiler chickens fed the virginiamycin also had higher plasma immunoglobulin levels at $35 \mathrm{~d}$ of age compared to the control group, which might contribute to the improved growth performance.

In a study in which 3-week old turkeys were inoculated with several viruses and bacteria to induce respiratory diseases, a five-day treatment with amoxicillin, compared with the untreated group, did not cause a significant reduction in any of the measured immune related parameters [68]. The authors suggested that the bactericidal effect of amoxicillin is being diminished by its less efficient distribution throughout tissues and its relatively fast elimination, as compared to enrofloxacin and florfenicol, which were also included in that study. 
In addition to the effect of antibiotics on performance, it has already been shown that a single therapeutic dose of amoxicillin for 24 hours in day old chicks has a negative effect on immune development [69]. In that study, numerically higher microbial diversity was observed in the antibiotic treated group at $5 \mathrm{~d}$ of age, as well as lower gene expression of immune related processes at $5 \mathrm{~d}$ of age, and subsequently a decreased number of macrophage-like cells in the mucosa at $14 \mathrm{~d}$ of age. In the present study, amoxicillin was administered from 0 to $7 \mathrm{~d}$ of age in the drinking water, and therefore a continuous pressure on the resident microbiota was established. Also a numerically higher diversity in microbiota (Shannon index) was observed in the current study, contrary to a previous study [69]. In the jejunum, Enterococcus was decreased to $0.3 \%$ ARC (4.9\% ARC in CON). Enterococci, lactic acid producing bacteria, are important colonizers immediately after hatch, and up to $70-80 \%$ ARC is observed for different genetic lines (Cobb) [70]. In humans they are abundant and of commensal nature, however, they are also potentially pathogenic and have intrinsic (and acquired) mechanisms for antibiotic resistance and virulence factors [71]. Thus far, it is not known what the specific role of these bacteria is in the programming of the immune system.

Contrary to Enterococci, Enterobacteriaceae were increased in ANT 6.6\% ARC compared to the unchallenged control $1.0 \%$ or challenged control $0.4 \%$ ARC. Members of the Enterobacteriaceae family are 'normal' residents of the gut. However, some of the species can produce endotoxins, which could be harmful to the host. Only the genus was identified in data analysis for the current study and therefore it is not possible to further characterize or interpret this without too much speculation.

Growth performance and microbiota composition in the jejunum at $7 \mathrm{~d}$ of age were significantly different between the antibiotic and control treatment, which was also reflected in the gene expression results. Multiple pathways were significantly enriched when comparing the two treatments and by superimposing the fold change data, striking differences in specific pathways of interest, i.e. PI3K-AKT, NFkB signalling pathway, cytokine-cytokine receptor interactions, and intestinal immune network for I gA production were observed. The PI3K-AKT pathway is involved in regulating cell cycle. The PI3K-AKT pathway is activated by many types of cellular stimuli or toxic insults and regulates fundamental cellular functions such as transcription, translation, proliferation, growth, and survival. These pathways can also regulate tight junctions in the gut by Toll-like receptor 2 (TLR2) [72] and play a key role in the modulation of immune responses [73, 74]. Thus, the relative higher expression for the antibiotic treatment could indicate that the barrier function is enhanced, or enhanced ECM regulation, or that the inflammatory response is modulated. To further investigate the latter, we also focused on the NFkB signalling pathway, cytokine-cytokine receptor interactions, and intestinal immune network for IgA production. In these pathways, a relatively lower expression of genes was observed for the antibiotic treatment compared to the (un)challenged controls. The NFkB signalling pathway regulates genes that are involved in immunity, inflammation, and cell survival. Thus, these data suggest that the antibiotic treatment has a decreased inflammation compared to control treatment. Similarly, less secretory IgA will be produced for the antibiotic treatment compared to the control treatment. Consequently, this may result in less entrapped dietary antigens and microorganisms in the mucus and neutralization of (endo)toxins $[75,76]$. Whereas the cytokine-cytokine receptor interactions are involved in innate and adaptive inflammatory host response, cell growth, differentiation, cell death, angiogenesis, and wound healing. These cytokines and their receptors can be categorized by structure into different families. In our analysis we mainly observed lower expression regarding immune related cytokines in the antibiotic group compared to the (un)challenged controls, whereas higher expression was observed in families involved in ECM and/or wound healing related processes.

Taken together, the gene expression data suggest that broiler chickens from the control treatment showed higher gene expression in NFkB signalling and slgA, and lower expression in PI3K-AKT/mTOR pathways. This could mean that there are different mechanisms for the host to maintain a certain homeostatic state during microbiota colonization and immune system programming in early life. In the current study, broiler chickens from the antibiotic treatment had a higher villi to crypt ratio at $7 \mathrm{~d}$ of age compared to control chickens. Low V:C ratios, are associated with infection and are being considered as detrimental for the host [77]. Current differences in V: C ratio (5.1 vs. 4.5) may be significant, but the biological read-out is still in the range of a well-functioning gut. In conclusion, administrating antibiotics in the first week boosts the short-term performance, changes the microbiota composition, modulates genes involved in barrier and immune function, and affects the intestinal morphology. 


\subsection{Rye}

Rye-fed broiler chickens had a reduced daily gain during the first week of life compared to the unchallenged control treatment, whereas feed intake did not differ and the gain to feed ratio only tended to differ. The reduction in daily gain was in line with our expectations, because dietary inclusion of rye will increase viscosity of intestinal digesta, consequently impairing digestibility and absorption of dietary nutrients and leading to a depression in growth performance [21-23]. After the first week of age, none of the growth performance parameters of the rye treatment differed from the challenged birds fed the control diet. This indicates that feeding the rye-enriched starter diet had only temporary effects on growth performance. In literature, no experiments could be found that studied the temporarily supplementation of rye in broilers, meaning that it was not possible to compare current performance results with that of other findings.

Microbiota diversity and overall composition did not significantly differ between the rye treatment and the controls. However, the focused investigation on genera level, resulted in 13 significantly different bacterial genera, dominated by members of Clostridia and Bacilli. Quantification of the microbiota by qPCR resulted in 10-fold more microbiota in the rye treatment compared to the (un)challenged control treatment. It is hypothesized that this could be due to the fact that the intestinal content is more viscous, resulting in a slower passage rate and consequently change the microbiota composition [78]. However, this change in microbiota did not result in significant changes in either gene expression or histology in jejunum at $7 \mathrm{~d}$ of age, between the rye and control treatment.

In conclusion, inclusion of rye affected growth performance, but only during the age period it was provided and without carry over effects to later age. Certain bacterial genera were significantly affected, and the total amount of microbiota was increased compared to the control treatment.

\section{$4.4 \quad$ Butyrate}

In the current study, growth performance of the challenged broiler chickens fed the butyrate supplemented diet did not differ from the challenged broiler chickens fed the control diet. In contrast, another study showed that the addition of Na-butyrate, encapsulated in palm fat, to the feed of experimentally infected broilers with NE resulted in increased final body weight, at $35 \mathrm{~d}$ of age, whereas there was a tendency to reduced total feed consumption, improved feed conversion ratio, reduced cumulative mortality, and increased production number compared to the infected broilers fed the control diet [79]. In that study, however, broiler chickens received the butyrate supplemented diet during the whole experimental period ( 0 to $35 \mathrm{~d}$ of age), whereas in the current study the butyrate was fed only for the first 7 days. Apparently, there was no preventive effect of the short-term provision of butyrate on performance at later age, when challenged with necrotic enteritis. In a study of Jerzsele et al. [80], however, BW of NE infected broiler chickens fed coated butyrate during the entire experiment was not different compared to the BW of infected birds fed the control diet.

The microbiota diversity and overall composition at $7 \mathrm{~d}$ of age were not significantly affected by the butyrate treatment, in both jejunum and colon. When testing for individual bacterial genera, four genera in the jejunum and four genera in the colon were observed that were significantly different between the butyrate and control treatment. In the jejunum the following four were significanlty different: Clostridiaceae candidatus.arthromitus, Lachnospiraceae blautia, and Lachnospiraceae dorea, and a non-classified species. Whereas in colon, Enterococcaceae, Clostridaceae SBM53, Veillonellaceae Veillonella and Enterobacteriaceae were significantly different. All these observed bacterial groups encompass large families with diverse functions and are therefore not helpful in the biological interpretation, in other words there is still much functional annotation necessary to make these data more valuable. Gene expression and jejunum histology at $7 \mathrm{~d}$ of age did not show any significant effects between the butyrate and control treatment.

In conclusion, inclusion of butyrate did not affect growth performance. However, certain bacterial genera were significantly affected, but still lack the proper functional annotation. 


\subsection{Beta-glucans}

In the current study, growth performance parameters of challenged broiler chickens fed the $\beta$-glucans supplemented diet did not differ from the challenged broiler chickens fed the control diet. Contrary to these findings in our study, in a study of Tian et al. [81], NE infected broiler chickens fed a $\beta$-glucansupplemented diet had significantly increased body weight ( 13 to 21 and 0 to $42 \mathrm{~d}$ of age), improved feed efficiency ( 13 to 21 and 21 to $42 \mathrm{~d}$ of age), increased antibody levels against $C$. perfringens, and improved villi height and villi height to crypt depth ratio. In addition, infected broiler chickens that were supplemented with $\beta$-glucans had markedly reduced intestinal $C$. perfringens counts, and NE related lesion scores in the gut compared with infected broiler chickens fed the control diet. In that study [81], however, broiler chickens received the supplemented diet during the entire grow-out period ( 0 to $42 \mathrm{~d}$ of age), whereas broiler chickens in the current study were fed the $\beta$-glucans only for the first $7 \mathrm{~d}$ of age. Apparently, there was no effect of the short-term provision of $\beta$-glucans on performance at later age, when challenged with necrotic enteritis.

Microbiota diversity and overall composition did not significantly differ between the $\beta$-glucans and control treatment. However, when zooming into the bacterial genera level we did observe a significant difference in the genus Lactobacillus. The $\beta$-glucans treatment showed a decreased ARC (78.4\%) compared to the unchallenged and challenged controls, respectively $88.7 \%$ and $89.2 \%$ ARC. We observed a significant increase in the ARC of Enterococcaceae in the antibiotic group compared to the unchallenged controls, however the ARC were relatively low around $0.01 \%$. Like Lactobacillus,

Enterococcaceae are also lactic acid producers, this suggests that maybe the decrease in Lactobacillus is compensated by an increase in Enterococcaceae. Gene expression and jejunum histology at $7 \mathrm{~d}$ of age did not show any significant effects between the $\beta$-glucans and control treatment.

In conclusion, inclusion of $\beta$-glucans did not affect growth performance. The observed difference in the genus Lactobacillus probably also does not functionally affect the gut system.

\subsection{Quantitative disease phenotype}

Despite the clear differences in the antibiotics group compared to the control group, in for example intestinal microbiota composition, host gene expression, and gut morphology, no significant differences were observed in the quantitative disease phenotype. However based on the birds positive for lesions, the antibiotic group scored lowest for lesions originating from both Eimeria maxima and Clostridium perfringens, respectively $12 \%$ and $4 \%$ lower than the challenged control. In addition, the antibiotic group also showed no birds or the least amount of birds having a severe score compared to all other groups including the challenged control.

It could be that the NE challenge model is too severe for the gut system and therefore no differences were observed when comparing challenged controls versus challenged birds that received antibiotics. A limitation to the correlation of the immune competence status to the quantitative disease phenotype is that the sacrificed birds on day 7 are of course different from the sacrificed birds for the quantitative disease phenotype on day 14 . 


\subsection{Concluding remarks and future research}

Except for the antibiotic treatment, providing diets enriched with rye, beta-glucans or coated butyrate during the first week of age, followed by an NE-challenge, did not show a programming effect on immune competence-related parameters.

The other objective of investigating the correlation between immune competence parameters before the NE challenge and the read-out of the NE challenge, so called quantitative disease phenotype, was not apparent. In retrospect, maybe the applied 'synchronized' challenge was too harsh on the gut system to measure the 'small' differences in immune competence by the different feed interventions.

Possible next steps could be to investigate the relation between the host gene expression and the gut microbiota, so-called correlation analysis. In addition, a data mining approach would also be worthwhile because of the plethora of data generated within this project. Furthermore, the current project investigated the immune competence development in great detail, it could also be interesting to see the different (immune) responses of the host on day 15 regarding the host gene expression and gut microbiota, in other words the 'molecular side' of the quantitative disease phenotype. In addition to the more local derived phenotypic aspects, mostly regarding (parts of the) gut, it is possible to generate data in blood. With these blood metabolite profiles one could investigate the systemic effects of the (dietary) intervention.

The results obtained in this study were used as input for the VDI-10 project in which a 'ruler' for immune competence has been designed and further tested. For example, the transcriptomics and microbiota data are fully integrated in the VDI-10 project, and also re-analysed to make these data comparable to the other datasets. The histology results are also used to fill the immune competence 'ruler'. 
1. EFSA/ECDC, The European Union summary report on antimicrobial resistance in zoonotic and indicator bacteria from humans, animals and food in 2015. EFSA Journal 2017; 15(2) : 4694, 212 pp. 2017.

2. Landers, T.F., et al., A Review of Antibiotic Use in Food Animals: Perspective, Policy, and Potential. Public Health Reports, 2012. 127(1): p. 4-22.

3. Mevius, D. and D. Heederik, Reduction of antibiotic use in animals "let's go Dutch". Journal Fur Verbraucherschutz Und Lebensmittelsicherheit-J ournal of Consumer Protection and Food Safety, 2014. 9(2): p. 177-181.

4. Klasing, K.C., Nutrition and the immune system. British Poultry Science, 2007. 48(5): p. 525-537.

5. Kidd, M.T., Nutritional modulation of immune function in broilers. Poultry Science, 2004. 83(4): p. 650-657.

6. Bar-Shira, E. and A. Friedman, Development and adaptations of innate immunity in the gastrointestinal tract of the newly hatched chick. Developmental and Comparative Immunology, 2006. 30(10): p. 930-941.

7. Bar-Shira, E., D. Sklan, and A. Friedman, Establishment of immune competence in the avian GALT during the immediate post-hatch period. Developmental and comparative immunology, 2003. 27(2): p. 147-57.

8. Schokker, D., et al., Gene expression patterns associated with chicken jejunal development. Developmental and Comparative Immunology, 2009. 33(11): p. 1156-1164.

9. Mulder, I.E., et al., Restricting Microbial Exposure in Early Life Negates the Immune Benefits Associated with Gut Colonization in Environments of High Microbial Diversity. Plos One, 2011. 6(12): p. 10 .

10. Mulder, I.E., et al., Environmentally-acquired bacteria influence microbial diversity and natural innate immune responses at gut surfaces. Bmc Biology, 2009. 7: p. 20.

11. Schokker, D., et al., Early-Life Environmental Variation Affects Intestinal Microbiota and Immune Development in New-Born Piglets. Plos One, 2014. 9(6): p. 16.

12. Simon, K., et al., Long-term effects of early life microbiota disturbance on adaptive immunity in laying hens. Poultry Science, 2016. 95(7): p. 1543-1554.

13. Penders, J., et al., Gut microbiota composition and development of atopic manifestations in infancy: the KOALA Birth Cohort Study. Gut, 2007. 56(5): p. 661-7.

14. Penders, J., et al., Factors influencing the composition of the intestinal microbiota in early infancy. Pediatrics, 2006. 118(2): p. 511-21.

15. Reynolds, L.A. and B.B. Finlay, A case for antibiotic perturbation of the microbiota leading to allergy development. Expert Review of Clinical Immunology, 2013. 9(11): p. 1019-1030.

16. Medical dictionary, http://medical-dictionary.thefreedictionary.com/immune+competence, 2017.

17. Abid, S.A., et al., EMERGING THREAT OF NECROTIC ENTERITIS IN POULTRY AND ITS CONTROL WITHOUT USE OF ANTIBIOTICS: A REVIEW. Journal of Animal and Plant Sciences, 2016. 26(6): $p$. 1556-1567.

18. Klaudia, C. and W. Alina, The influence of enrofloxacin, florfenicol, ceftiofur and E. coli LPS interaction on $T$ and $B$ cells subset in chicks. Veterinary Research Communications, 2015. 39(1): p. 53-60.

19. Anadon, A., et al., Pharmacokinetics of amoxicillin in broiler chickens. Avian Pathology, 1996. 25(3): p. 449-458.

20. Smits, C.H.M. and G. Annison, Non-starch plant polysaccharides in broiler nutrition - Towards a physiologically valid approach to their determination. Worlds Poultry Science Journal, 1996. 52(2): p. 203-221.

21. Jozefiak, D., et al., Effects of dietary inclusion of triticale, rye and wheat and xylanase supplementation oil growth performance of broiler chickens and fermentation in the gastrointestinal tract. Animal Feed Science and Technology, 2007. 132(1-2): p. 79-93.

22. Antoniou, T. and R.R. Marquardt, Influence of Rye Pentosans on the Growth of Chicks. Poultry Science, 1981. 60(8): p. 1898-1904.

23. Bedford, M.R. and H.L. Classen, An in vitro assy for prediction of broiler intestinal viscosity and growth when fed rye-based diets in the presence of exogenous enzymes. Poultry Science, 1993. 72(1): p. 137-143.

24. Satchithanandam, S., et al., Alterations in rat intestinal mucin patterns following luminal infusion of acetylsalicylic-acid and prostaglandin derivates. Digestive Diseases and Sciences, 1990. 35(12): p. 1518-1527.

25. Johnson, I.T. and J.M. Gee, Gastrointestinal adaptation in response to soluble non-available polysaccharides in the rat. British Journal of Nutrition, 1986. 55(3): p. 497-505. 
26. Choct, M., G. Annison, and R.P. Trimble, Soluble wheat pentosans exhibit different antinutritive activities in intact and cecectomized broiler-chickens. Journal of Nutrition, 1992. 122(12): p. 24572465.

27. Van der Klis, J.D. and A. Van Voorst, The effect of carboxy methyl cellulose (a soluble polysaccharide) on the rate of marker excretion from the gastrointestinal-tract of broilers. Poultry Science, 1993. 72(3): p. 503-512.

28. Teirlynck, E., et al., The cereal type in feed influences gut wall morphology and intestinal immune cell infiltration in broiler chickens. British Journal of Nutrition, 2009. 102(10): p. 1453-1461.

29. Smits, C.H.M., et al., The antinutritive effect of a carboxymethylcellulose with high viscosity on lipid digestibility in broiler chickens is not associated with mucosal damage. Journal of Animal Physiology and Animal Nutrition-Zeitschrift Fur Tierphysiologie Tierernahrung Und Futtermittelkunde, 2000. 83(4-5): p. 239-245.

30. Viveros, A., et al., EFFECT OF ENZYME SUPPLEMENTATION OF A DIET BASED ON BARLEY, AND AUTOCLAVE TREATMENT, ON APPARENT DIGESTIBILITY, GROWTH-PERFORMANCE AND GUT MORPHOLOGY OF BROILERS. Animal Feed Science and Technology, 1994. 48(3-4): p. 237-251.

31. Danicke, S., et al., Replacement of soybean oil with tallow in rye-based diets without xylanase increases protein synthesis in small intestine of broilers. Journal of Nutrition, 2000. 130(4): p. 827834.

32. Chae, B.J., et al., Effects of supplementation of beta-glucan on the growth performance and immunity in broilers. Research in Veterinary Science, 2006. 80(3): p. 291-298.

33. Chen, J.Z. and R. Seviour, Medicinal importance of fungal beta-( $1->3),(1->6)$-glucans. Mycological Research, 2007. 111: p. 635-652.

34. Guo, Y.M., R.A. Ali, and M.A. Qureshi, The influence of beta-glucan on immune responses in broiler chicks. Immunopharmacology and Immunotoxicology, 2003. 25(3): p. 461-472.

35. Taylor, P.R., et al., The beta-glucan receptor, dectin-1, is predominantly expressed on the, surface of cells of the monocyte/macrophage and neutrophil lineages. Journal of Immunology, 2002. 169(7): p. 3876-3882.

36. Cheng, Y.H., et al., Effects of beta-glucan supplementation on lymphocyte proliferation, macrophage chemotaxis and specific immune responses in broilers. Asian-Australasian Journal of Animal Sciences, 2004. 17(8): p. 1145-1149.

37. Morales-Lopez, R., et al., Use of yeast cell walls; beta-1, 3/1, 6-glucans; and mannoproteins in broiler chicken diets. Poultry Science, 2009. 88(3): p. 601-607.

38. An, B.K., et al., Growth performance and antibody response of broiler chicks fed yeast derived betaglucan and single-strain probiotics. Asian-Australasian Journal of Animal Sciences, 2008. 21(7): p. 1027-1032.

39. Cox, C.M., et al., Performance and immune responses to dietary beta-glucan in broiler chicks. Poultry Science, 2010. 89(9): p. 1924-1933.

40. Shashidhara, R.G. and G. Devegowda, Effect of dietary mannan oligosaccharide on broiler breeder production traits and immunity. Poultry Science, 2003. 82(8): p. 1319-1325.

41. Spring, P., et al., The effects of dietary mannanoligosaccharides on cecal parameters and the concentrations of enteric bacteria in the ceca of Salmonella-challenged broiler chicks. Poultry Science, 2000. 79(2): p. 205-211.

42. Stanley, V.G., C. Brown, and A.E. Sefton, Comparative evaluation of a yeast culture, mannanoligosaccharide and an antibiotic on performance of turkeys. Poultry Science, 2000. 79(Suppl. 1: 117 (abstract)).

43. Parks, C.W., et al., The effect of mannanoligosaccharides, bambermycins, and virginiamycin on performance of large white male market turkeys. Poultry Science, 2001. 80(6): p. 718-723.

44. Wei, D., D. Williams, and W. Browder, Activation of AP-1 and SP1 correlates with wound growth factor gene expression in glucan-treated human fibroblasts. International Immunopharmacology, 2002. 2(8): p. 1163-1172.

45. Dipietro, L.A., WOUND-HEALING - THE ROLE OF THE MACROPHAGE AND OTHER IMMUNE CELLS. Shock, 1995. 4(4): p. 233-240.

46. Browder, W., et al., EFFECT OF ENHANCED MACROPHAGE FUNCTION ON EARLY WOUND-HEALING. Surgery, 1988. 104(2): p. 224-230.

47. Compton, R., D. Williams, and W. Browder, The beneficial effect of enhanced macrophage function on the healing of bowel anastomoses. American Surgeon, 1996. 62(1): p. 14-18.

48. Portera, C.A., et al., Effect of macrophage stimulation on collagen biosynthesis in the healing wound. American Surgeon, 1997. 63(2): p. 125-130.

49. Delatte, S.J., et al., Effectiveness of beta-glucan collagen for treatment of partial-thickness burns in children. Journal of Pediatric Surgery, 2001. 36(1): p. 113-118.

50. Thorum, S.C., et al., Dietary $(1,3 / 1,6)$-beta-D-glucan decreases transforming growth factor beta expression in the lung of the neonatal piglet. Nutrition Research, 2013. 33(4): p. 322-331. 
51. Cerisuelo, A., et al., The impact of a specific blend of essential oil components and sodium butyrate in feed on growth performance and Salmonella counts in experimentally challenged broilers. Poultry Science, 2014. 93(3): p. 599-606.

52. Moquet, P.C.A., et al., I mportance of release location on the mode of action of butyrate derivatives in the avian gastrointestinal tract. Worlds Poultry Science Journal, 2016. 72(1): p. 61-80.

53. Barnes, P.J. and M. Karin, Nuclear factor-kappaB: a pivotal transcription factor in chronic inflammatory diseases. The New England J ournal of Medicine, 1997. 336: p. 1066-1071.

54. Moeinian, M., et al., Synergistic effect of probiotics, butyrate and I-Carnitine in treatment of IBD. Journal of Medical Hypotheses and Ideas, 2013. 7: p. 50-53.

55. Sunkara, L.T., et al., Butyrate Enhances Disease Resistance of Chickens by Inducing Antimicrobial Host Defense Peptide Gene Expression. Plos One, 2011. 6(11): p. 10.

56. Meijer, K., P. de Vos, and M.G. Priebe, Butyrate and other short-chain fatty acids as modulators of immunity: what relevance for health? Current Opinion in Clinical Nutrition and Metabolic Care, 2010. 13(6): p. 715-721.

57. Zhang, W.H., et al., Sodium butyrate maintains growth performance by regulating the immune response in broiler chickens. British Poultry Science, 2011. 52(3): p. 292-301.

58. Caporaso, J.G., et al., QIIME allows analysis of high-throughput community sequencing data. Nat Methods, 2010. 7(5): p. 335-6.

59. McDonald, D., et al., An improved Greengenes taxonomy with explicit ranks for ecological and evolutionary analyses of bacteria and archaea. ISME J, 2012. 6(3): p. 610-8.

60. DeSantis, T.Z., et al., Greengenes, a chimera-checked 16S rRNA gene database and workbench compatible with ARB. Appl Environ Microbiol, 2006. 72(7): p. 5069-72.

61. Haas, B.J., et al., Chimeric 16S rRNA sequence formation and detection in Sanger and 454pyrosequenced PCR amplicons. Genome Res, 2011. 21(3): p. 494-504.

62. Kauffmann, A., R. Gentleman, and W. Huber, arrayQualityMetrics--a bioconductor package for quality assessment of microarray data. Bioinformatics, 2009. 25(3): p. 415-6.

63. Gentleman, R.C., et al., Bioconductor: open software development for computational biology and bioinformatics. Genome biology, 2004. 5(10): p. R80.

64. Zhou, M.J., et al., Effects of Bacillus licheniformis on the growth performance and expression of lipid metabolism-related genes in broiler chickens challenged with Clostridium perfringens-induced necrotic enteritis. Lipids in Health and Disease, 2016. 15: p. 10.

65. M'Sadeq, S.A., et al., Dietary acylated starch improves performance and gut health in necrotic enteritis challenged broilers. Poultry Science, 2015. 94(10): p. 2434-2444.

66. Salim, H.M., et al., Supplementation of direct-fed microbials as an alternative to antibiotic on growth performance, immune response, cecal microbial population, and ileal morphology of broiler chickens. Poultry Science, 2013. 92(8): p. 2084-2090.

67. Ghosh, T.K., et al., Assessment of yeast cell wall as replacements for antibiotic growth promoters in broiler diets: effects on performance, intestinal histo-morphology and humoral immune responses. Journal of Animal Physiology and Animal Nutrition, 2012. 96(2): p. 275-284.

68. Marien, M., et al., Efficacy of enrofloxacin, florfenicol and amoxicillin against Ornithobacterium rhinotracheale and Escherichia coli $\mathrm{O} 2: \mathrm{K} 1$ dual infection in turkeys following APV priming. Veterinary Microbiology, 2007. 121(1-2): p. 94-104.

69. Schokker, D., et al., Perturbation of microbiota in one-day old broiler chickens with antibiotic for 24 hours negatively affects intestinal immune development. BMC Genomics, 2017. 18(1): p. 241.

70. Schokker, D., et al., Early life microbial colonization of the gut and intestinal development differ between genetically divergent broiler lines. BMC Genomics, 2015. 16: p. 418.

71. Hollenbeck, B.L. and L.B. Rice, Intrinsic and acquired resistance mechanisms in enterococcus. Virulence, 2012. 3(5): p. 421-33.

72. Cario, E., G. Gerken, and D.K. Podolsky, Toll-like receptor 2 controls mucosal inflammation by regulating epithelial barrier function. Gastroenterology, 2007. 132(4): p. 1359-74.

73. Weichhart, T., M. Hengstschlager, and M. Linke, Regulation of innate immune cell function by mTOR. Nat Rev Immunol, 2015. 15(10): p. 599-614.

74. Dibble, C.C. and B.D. Manning, Signal integration by mTORC1 coordinates nutrient input with biosynthetic output. Nat Cell Biol, 2013. 15(6): p. 555-64.

75. Mantis, N.J., N. Rol, and B. Corthesy, Secretory IgA's complex roles in immunity and mucosal homeostasis in the gut. Mucosal Immunol, 2011. 4(6): p. 603-11.

76. Pabst, O., V. Cerovic, and M. Hornef, Secretory IgA in the Coordination of Establishment and Maintenance of the Microbiota. Trends Immunol, 2016. 37(5): p. 287-96.

77. Pan, D. and Z. Yu, Intestinal microbiome of poultry and its interaction with host and diet. Gut Microbes, 2014. 5(1): p. 108-19.

78. Tellez, G., et al., Rye affects bacterial translocation, intestinal viscosity, microbiota composition and bone mineralization in Turkey poults. PLoS One, 2015. 10(4): p. e0122390. 
79. Eshak, M.G., et al., The efficacy of Na-butyrate encapsulated in palm fat on performance of broilers infected with necrotic enteritis with gene expression analysis. Veterinary World, 2016. 9(5): p. 450457.

80. Jerzsele, A., et al., Efficacy of protected sodium butyrate, a protected blend of essential oils, their combination, and Bacillus amyloliquefaciens spore suspension against artificially induced necrotic enteritis in broilers. Poultry Science, 2012. 91(4): p. 837-843.

81. Tian, X.Y., et al., Effects of dietary yeast beta-glucans supplementation on growth performance, gut morphology, intestinal Clostridium perfringens population and immune response of broiler chickens challenged with necrotic enteritis. Animal Feed Science and Technology, 2016. 215: p. 144-155. 


\section{Appendix A}

Figure legend: Cross-section of jejunum of broiler (day 7)

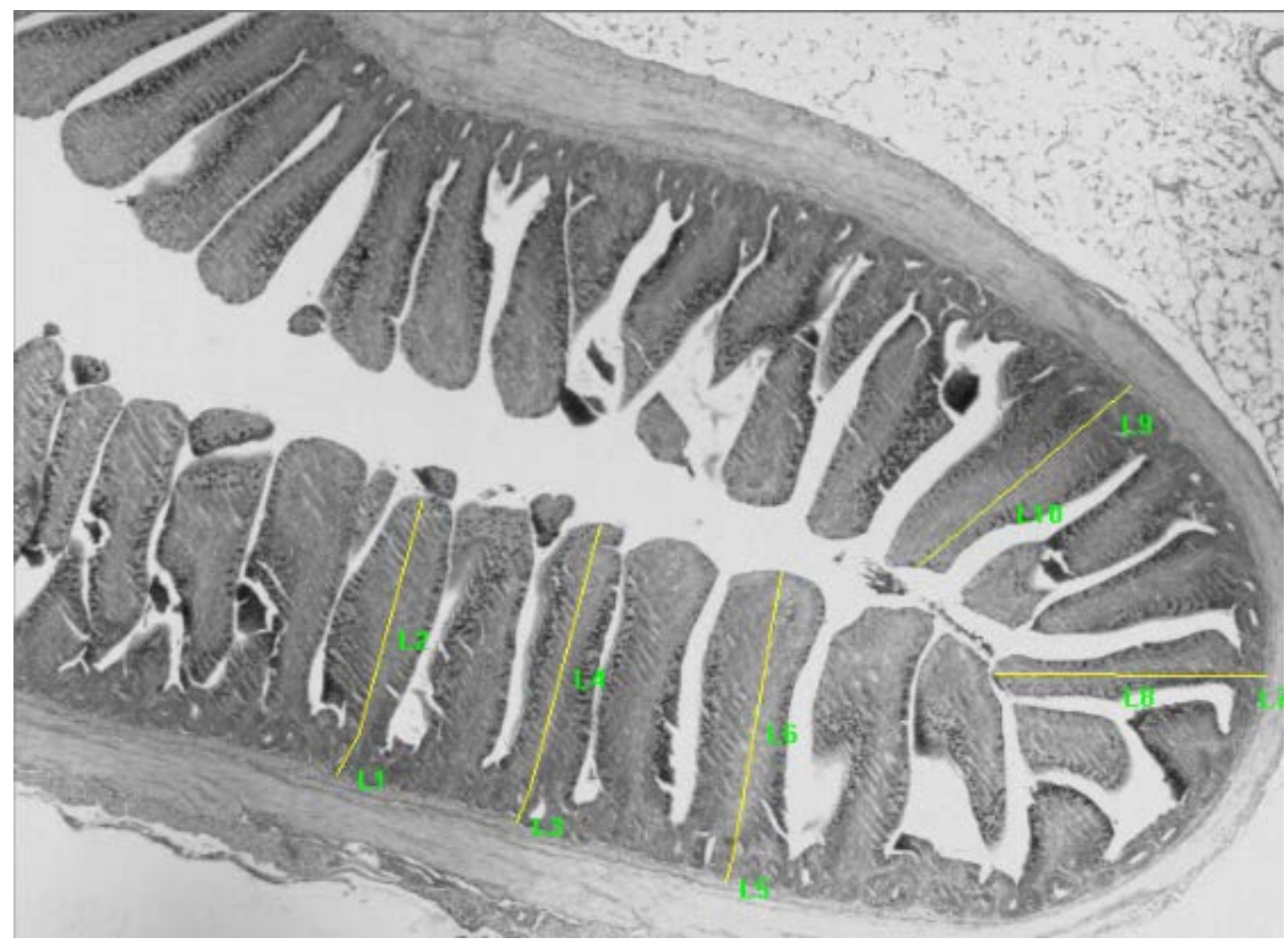

The yellow lines indicate either crypt depths (L1, L3, L5, L7, L9) or villi height (L2, L4, L6, L8, L10) in $\mu \mathrm{m}$.

\section{Appendix B}

More explanation of Figures 4-7.

The top panel shows the Kyoto Encyclopedia of Genes and Genomes (KEGG) pathway of interest (indicated in the top left box), the green rectangles indicate genes or gene complexes, open circles indicate other molecules (mostly chemical compounds), and the white boxes with rounded edges depict links to other pathways. Solid arrows indicate molecular interactions, whereas dashed lines indicate indirect effects. Within the protein-protein interactions (between boxes) different activities are distinguished, $+p$ is phosphorylation, $-p$ dephosphorylation, $+\mathrm{u}$ is ubiquitination, $+\mathrm{g}$ is glycosylation, $+m$ is methylation, see box below for the other activities.

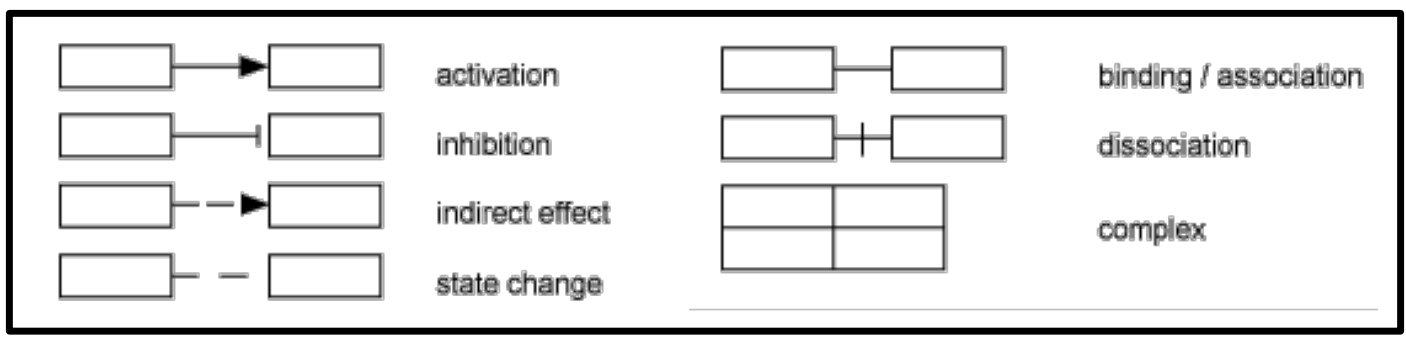

In the bottom panel, a replica is generated based on the KEGG pathway, however small differences in lay-out can occur. The rectangles are now coloured based on their fold change between the antibiotic and control group. Blue denotes down-regulated genes and red denotes up-regulated genes, more intense colours depict a higher value i.e. down-regulation or up-regulation. Grey rectangles denote that these genes were not present on our platform, in other words they were not measured by our transcriptomic analysis. The bottom panel shows in one overview that different parts of a pathway can be up- or down-regulated and because different parts of a pathway can link to different biological functions. These representations help in further interpreting the underlying biological mechanisms. 



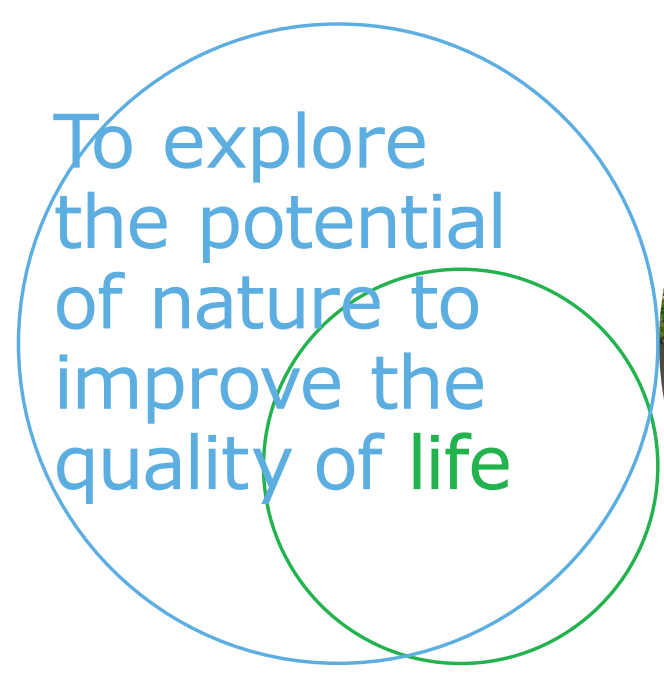

Wageningen Livestock Research P.O. Box 338

$6700 \mathrm{AH}$ Wageningen

The Netherlands

$T+31(0) 317483953$

E info.livestockresearch@wur.nl www.wur.nl/livestock-research

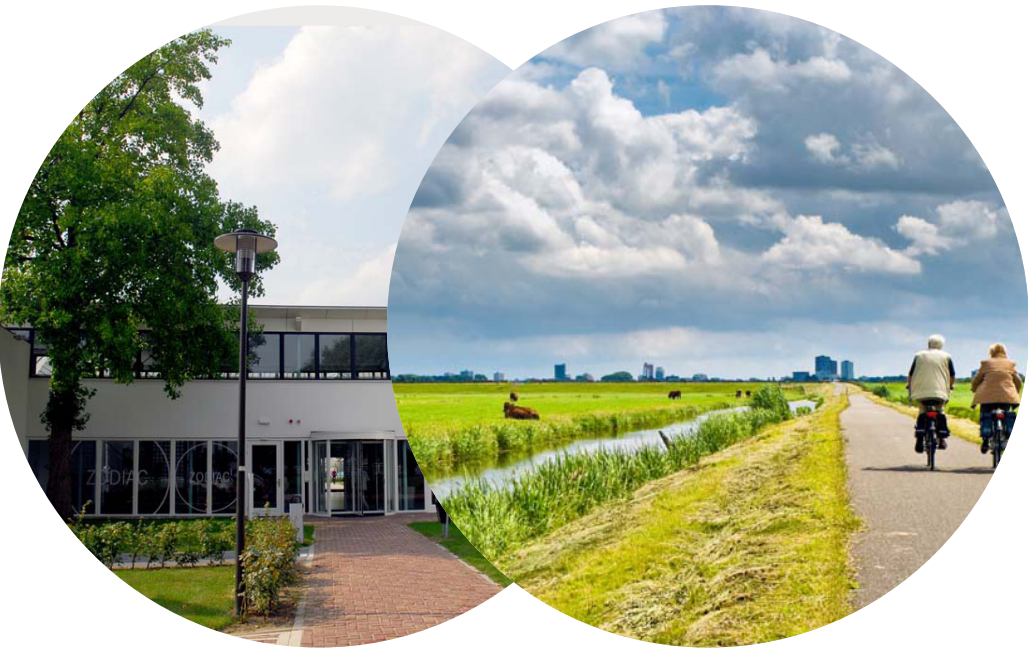

Wageningen Livestock Research creates science based solutions for a sustainable and profitable livestock sector. Together with our clients, we integrate scientific knowledge and practical experience to develop livestock concepts for future generations.

Wageningen Livestock Research is part of Wageningen University \& Research. Together we work on the mission: 'To explore the potential of nature to improve the quality of life'. A staff of 6,500 and 10,000 students from over 100 countries are working worldwide in the domain of healthy food and living environment for governments and the business community-at-large. The strength of Wageningen University \& Research lies in its ability to join the forces of specialised research institutes and the university. It also lies in the combined efforts of the various fields of natural and social sciences. This union of expertise leads to scientific breakthroughs that can quickly be put into practice and be incorporated into education. This is the Wageningen Approach. 